\title{
A multiscale mechanobiological model of bone remodelling predicts site-specific bone loss in the femur during osteoporosis and mechanical disuse
}

\author{
C. Lerebours · P. R. Buenzli • S. Scheiner - P. Pivonka
}

Received: date / Accepted: date

\begin{abstract}
We propose a multiscale mechanobiological model of bone remodelling to investigate the site-specific evolution of bone volume fraction across the midshaft of a femur. The model includes hormonal regulation and biochemical coupling of bone cell populations, the influence of the microstructure on bone turnover rate, and mechanical adaptation of the tissue. Both microscopic and tissue-scale stress/strain states of the tissue are calculated from macroscopic loads by a combination of beam theory and micromechanical homogenisation.

This model is applied to simulate the spatio-temporal evolution of a human midshaft femur scan subjected to two deregulating circumstances: (i) osteoporosis and (ii) mechanical disuse. Both simulated deregulations led to endocortical bone loss, cortical wall thinning and expansion of the medullary cavity, in accordance with experimental findings. Our model suggests that these observations are attributable to a large extent to the influence of the microstructure on bone turnover rate. Mechanical adaptation is found to help preserve intracortical bone matrix near the periosteum. Moreover, it leads to non-uniform cortical wall thickness due to the asymmetry of macroscopic loads introduced by the bending moment. The effect of mechanical adaptation near the endosteum can be greatly affected by whether
\end{abstract}

\section{Lerebours - P. R. Buenzli}

School of Mathematical Sciences, Monash University,

Clayton, VIC, Australia.

Tel.: +613-99-024002

E-mail: chloe.lerebours@monash.edu

\section{S. Scheiner}

Institute for Mechanics of Materials and Structures, Vienna University of Technology, Vienna, Austria.

P. Pivonka

Northwest Academic Centre, University of Melbourne,

St Albans, VIC, Australia. the mechanical stimulus includes stress concentration effects or not.

Keywords Bone remodelling · Site-specific bone loss . Trabecularisation - Multiscale modelling . Osteoporosis · Mechanical disuse

\section{Introduction}

Bone is a biomaterial with a complex hierarchical structure characterised by at least three distinct length scales: (i) the cellular scale $(10-20 \mu \mathrm{m})$; (ii) the tissue scale (2$5 \mathrm{~mm}$ ) and (iii) the whole organ scale $(4-45 \mathrm{~cm})$ [Rho et al (1998); Weiner and Wagner (1998)]. Several interactions exist between these scales, which affect bone remodelling, bone material properties and bone structural integrity. The activity of bone-resorbing and boneforming cells during bone remodelling leads to changes in material properties at the tissue scale which subsequently affect the distribution of loads at the structural, whole organ scale (Figure 1). Besides, changes in bone shape and microarchitecture modify the stress/strain distribution and bone surface availability, which provide mechanical and geometrical feedbacks onto the bone cells and, eventually, affect bone remodelling [Martin (1972); Lanyon et al (1982); Frost (1987)]. Due to the complexity of these interactions, the interpretation of experimental data at a single scale is difficult. Predicting the evolution of multifactorial bone disorders, such as osteoporosis, necessitates a comprehensive modelling approach in which these multiscale interactions are consistently integrated.

Various mathematical models of bone remodelling have been proposed in the literature. Biomechanics models estimating tissue-scale stress and strain distribution from musculoskeletal models and average material 
(a) Couplings in the bone remodelling process (b) Femur (c) Midshaft cross-section (d) Representative volume of the tissue at $r$
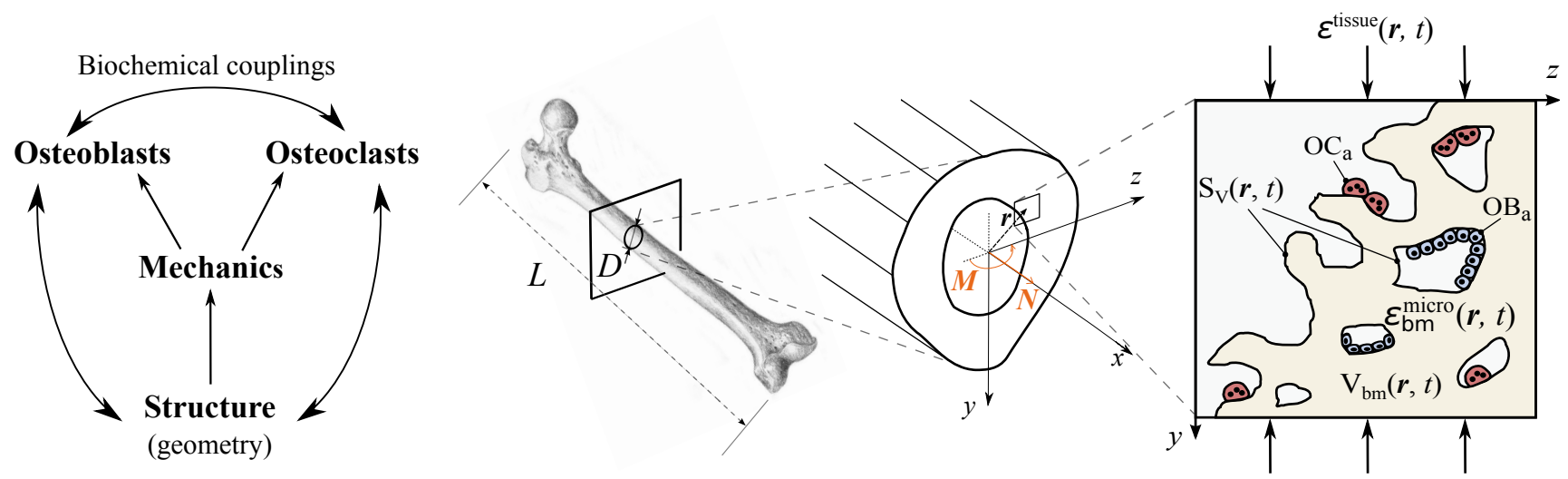

Fig. 1 Multiscale representation of bone. (a) Scheme of the couplings in the bone remodelling process; (b) Femur bone geometry (organ scale); (c) Midshaft cross section depicting coordinate axes and the sectional forces used for beam theory (tissue to organ scales); (d) Representative volume element (RVE) of cortical bone used to define bone cell densities, bone volume fraction, and specific surface (cellular to tissue scales).

properties, such as bone density, are often used in conjunction with remodelling algorithms based on Wolff's law. These remodelling algorithms locally increase or decrease bone density depending on the tissue's mechanical state [Carter and Hayes (1977); Carter and Beaupré (2001); Fyhrie and Carter (1986); Weinans et al (1992); Van der Meulen et al (1993); Pettermann et al (1997)]. Such models may also include damage accumulation due to fatigue loading and damage repair [Prendergast and Taylor (1994); McNamara and Prendergast (2007); García-Aznar et al (2005)]. Other models focus at the microstructural scale ( $\mu \mathrm{m}$ to $\mathrm{mm}$ ) and describe the evolution of trabecular bone microarchitecture through resorption and formation events at the bone surface induced by the local mechanical state [Huiskes et al (2000); Ruimerman et al (2005); Van Oers et al (2008); Christen et al $(2012,2013)]$. Most of these mathematical models focus on the biomechanical aspects of bone remodelling and do not consider hormonal regulation or biochemical coupling between bone cells.

In this paper, we propose a novel multiscale modelling approach of bone remodelling combining and extending several mathematical models into a consistent framework. This framework enables (i) the consideration of biochemical and cellular interactions in bone remodelling at the cellular scale [Lemaire et al (2004); Pivonka et al (2008); Buenzli et al (2012); Pivonka et al (2013)], (ii) the evolution of material properties at the tissue scale based on bone cell remodelling activities regulated by mechanical feedback [Scheiner et al (2013)] and bone surface availability [Pivonka et al (2013); Buenzli et al (2013)], and (iii) the determination of the stress/ strain distributions from the tissue scale to the mi- crostructural scale by a combination of generalised beam theory and micromechanical homogenisation [Hellmich et al (2008); Scheiner et al (2013); Buenzli et al (2013)].

This modelling approach is applied to simulate the temporal evolution of a human femoral bone at the midshaft (Figure 1), subjected to various deregulating circumstances such as osteoporosis and changes in mechanical loading. An initial state of normal bone remodelling is first assumed, in which the tissue across the midshaft cross section remodels at site-specific turnover rates without changing its average material properties. Osteoporosis is then simulated by hormonal changes deregulating the biochemical coupling between osteoclasts and osteoblasts. These hormonal changes are calibrated so as to reproduce realistic rates of osteoporotic bone loss. The strength of the resorptive and formative responses of bone cells to mechanical feedbacks are calibrated so as to reproduce rates of bone loss and recovery in cosmonauts undertaking long-duration space flight missions. A scan of a femur cross section is used as initial condition for our simulations. This illustrates the potential of our modelling approach to be used as a predictive, patient-specific diagnostic tool for estimating the deterioration of bone tissues. Here, we use the model to investigate the interplay between geometrical and mechanical feedbacks in inducing site-specific bone loss in osteoporosis, which is characterised by endocortical bone loss, cortical wall thinning, and the expansion of the marrow cavity [Feik et al (1997); Bousson et al (2001); Zebaze et al (2010)]. 


\section{Description of the model}

Figures 1 and 2 summarise the general approach of our model. We consider a portion of human femur near the midshaft. This portion of bone is assumed to carry loads corresponding to a total normal force $\boldsymbol{N}$ and total bending moment $\boldsymbol{M}$ (Figure 1(c)). These loads are distributed unevenly across the midshaft cross section depending on the site-specific bone microstructure, particularly on the cortical porosity [Zebaze et al (2010); Buenzli et al (2013)]. This load distribution determines a site-specific mechanical stimulus which is sensed and transduced by bone cells (Figure 2(a)). This mechanical feedback is incorporated in a cell population model as biochemical signals leading to changes in the balance between osteoclasts and osteoblasts (Figure 2(b)). In addition, microstructural parameters such as bone volume fraction $\left(f_{\mathrm{bm}}\right)$ and bone specific surface influence the propensity of bone cells to differentiate and become active [Martin (1984); Lerebours et al (2015)]. This geometrical feedback is included in the cell population model via a dependence of the bone turnover rate on the bone volume fraction. The activities of osteoclasts and osteoblasts modify the tissue microstructural parameters (bone volume fraction, bone specific surface), which in turn induces changes in the load distribution (Figure 2(c)). In the following, we introduce in more detail the multiple scales and related variables involved in this model workflow. Table 1, in Appendix A.2, lists all the parameters of the model.

\subsection{Load distribution from the organ scale to the} cellular scale

Loading is composed of body weight and muscle forces exerted onto bone via tendons and direct action of muscles. These forces can be calculated from bone shape, muscle and tendon attachment, and gait analysis data using musculoskeletal models [Lloyd and Besier (2003); Viceconti et al (2006); Martelli et al (2014)]. Continuum mechanics provides the link between external forces exerted onto a structure, and the strain and stress distribution in the structure [Salencon (2001)].

Tissue-scale properties within the framework of continuum mechanics are average mechanical properties over microstructural material phases and pores (presented in detail in the next sections). The corresponding tissue-scale stresses and strains may significantly deviate from the microscopic, cellular scale, stresses and strains acting in the different material phases composing the tissue due to so-called strain and stress concentration effects [Zaoui (2002); Hill (1963)]. Microscopic stress and strain distributions in the bone matrix are likely to be sensed directly by bone cells, particularly by osteocytes [Scheiner et al (2013)]. However, as osteocytes form an extensive interconnected network [Marotti (2000); Buenzli and Sims (2015)], they may also sense larger scale stress and strain distributions. We will let either the tissue-scale or the microscopic mechanical state of bone act onto the bone cells to investigate how this influences the site-specific evolution of bone tissue microstructures.

In the following, we present first how stress and strain distributions can be calculated at the tissue scale using beam theory. We then present how these tissuescale stress and strain distributions are employed as site-specific loading boundary conditions to the continuum micromechanical model of Hellmich et al (2008) for the calculation of microscopic stress and strain distributions effective at the cellular level.

\section{Determination of tissue-scale stress and strain distribu- tions based on beam theory}

The continuum mechanical field equations allow the calculation of tissue-scale strain and stress distributions in bone. Given that the length of the femur $L$ is significantly larger $(45-50 \mathrm{~cm})$ than its diameter $D(3-5 \mathrm{~cm})$ at the midshaft (Figure 1(b)) the continuum mechanical field equations can be approximated using beam theory formulated for small strains and generalised to materials of non-uniform properties, an approach we have used previously in Buenzli et al (2013).

This approach requires the knowledge of the total external forces, i.e., the normal force $\boldsymbol{N}$ and the bending moment $\boldsymbol{M}$ carried by the femur cross section. $\boldsymbol{N}$ and $\boldsymbol{M}$ can be estimated for different physical activities by using musculoskeletal models [Vaughan et al (1992); Forner-Cordero et al (2006)]. In our simulations we take constant values for $\boldsymbol{N}$ and $\boldsymbol{M}$ comparable with the maximum ground reaction force and knee and hip moments that occur during a gait analysis, estimated as: $\boldsymbol{N}=\left(N_{x}, 0,0\right), N_{x}=-700 \mathrm{~N}$, and $\boldsymbol{M}=M \hat{\boldsymbol{m}}, \mathrm{M}$ $=50 \mathrm{Nm}$, where $\hat{\boldsymbol{m}}$ is a unit vector along the anteroposterior axis of the cross section determined from the micro-radiograph [Vaughan et al (1992); Forner-Cordero et al (2006); Ruff (2000); Cordey and Gautier (1999)] (Figure $5(\mathrm{c})$ ). The $x$-axis is the femur's longitudinal axis and $(y, z)$ is the plane transverse to $x$ at the midshaft (Figure 1(b)-(c)).

Tissue-scale mechanical properties correspond to spatial averages over a so-called representative volume element (RVE) of the tissue. In cortical bone, an appropriate tissue RVE is of the order of $10 \times 2 \times 2 \mathrm{~mm}^{3}$, a size large enough to contain a large number of pores, but small enough to retain site-specific information and to not be influenced by macroscopic features such as 


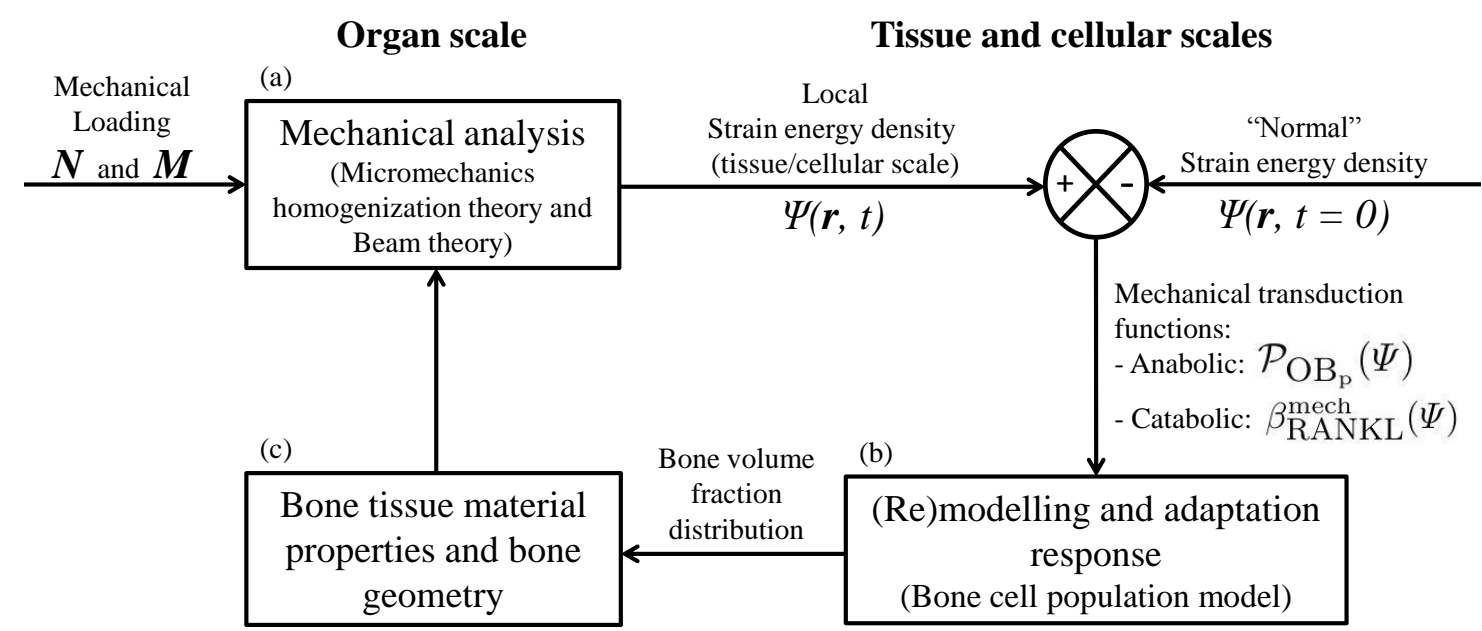

Fig. 2 Flow chart of bone remodelling simulations taking into account (a) the global mechanical loading, (b) the bone cell population model, and (c) the bone material and geometry adaptation.

overall bone shape [Hill (1963); Zaoui (2002)]. We denote by $\mathbb{C}^{\text {tissue }}(\boldsymbol{r}, t)$ the local bone tissue stiffness tensor defined at the RVE scale, where $\boldsymbol{r}$ denotes the location in bone of the RVE (Figure 1(c)) and the dependence on time $t$ reflects the fact that bone remodelling may modify the local mechanical properties of the tissue. This tissue-scale stiffness tensor is assumed to relate the tissue-scale stress tensor $\boldsymbol{\sigma}^{\text {tissue }}$ and strain tensor $\varepsilon^{\text {tissue }}$ pointwise according to Hooke's law:

$\boldsymbol{\sigma}^{\text {tissue }}(\boldsymbol{r}, t)=\mathbb{C}^{\text {tissue }}(\boldsymbol{r}, t): \varepsilon^{\text {tissue }}(\boldsymbol{r}, t)$.

Beam theory is based on the so-called Euler-Bernoulli kinematic hypothesis, which asserts that material cross sections initially normal to the beam's neutral axis remain planar, undeformed in their own plane, and normal to the neutral axis in the beam's deformed state [Timoshenko and Goodier (1951); Bauchau and Craig (2009); Hjelmstad (2005)]. These assumptions are expected to be well satisfied near the femoral midshaft under small deformations generated by bending and compression or tension. Furthermore, no shear force, torsional loads or twisting along the beam axis are assumed. These assumptions, Eq. (1), and the fact that bone is an orthotropic material [Hellmich et al (2004)] imply that the only nonzero components of the stress tensor are the normal stresses $\sigma_{x x}^{\text {tissue }}=\mathbb{C}_{1111}^{\text {tissue }} \varepsilon_{x x}^{\text {tissue }}, \sigma_{y y}^{\text {tissue }}=$ $\mathbb{C}_{1122}^{\text {tissue }} \varepsilon_{x x}^{\text {tissue }}$, and $\sigma_{z z}^{\text {tissue }}=\mathbb{C}_{1133}^{\text {tissue }} \varepsilon_{x x}^{\text {tissue }}$, where the normal stresses $\sigma_{y y}^{\text {tissue }}$ and $\sigma_{z z}^{\text {tissue }}$ are induced by compression or tension along the beam axis $x$ by the Poisson effect $^{1}$ (see Buenzli et al (2013) for more details). The

\footnotetext{
1 The stress components $\sigma_{y y}^{\text {tissue }}$ and $\sigma_{z z}^{\text {tissue }}$ do not participate directly to the transfer of the resultant force $\boldsymbol{N}$ and resultant bending moment $\boldsymbol{M}$ across the bone cross section, however, they are accounted for in the calculation of the tissuescale strain energy density $\Psi^{\text {tissue }}$.
}

Euler-Bernoulli hypothesis implies that the tissue strain tensor reduces to the single non-zero component $\varepsilon_{x x}^{\text {tissue }}$ and that:

$$
\varepsilon_{x x}^{\mathrm{tissue}}(y, z, t)=\varepsilon_{1}(t)-\kappa_{3}(t) y+\kappa_{2}(t) z,
$$

where $\varepsilon_{1}$ is the sectional axial strain, and $\kappa_{2}$ and $\kappa_{3}$ are the sectional beam curvatures about the $z$ - and $y$-axes, respectively [Bauchau and Craig (2009)]. The three unknowns $\varepsilon_{1}, \kappa_{2}$, and $\kappa_{3}$ are determined by the constraints that (i) the integral of $\sigma_{x x}^{\text {tissue }}$ over the midshaft cross section must give the total normal force $N_{x}$, and (ii) the integral of the stress moment $(0, y, z) \times \sigma_{x x}^{\text {tissue }} \hat{\boldsymbol{x}}$ must give the total bending moment $\boldsymbol{M}=M \hat{\boldsymbol{m}}$ (the axes origin in the $(y, z)$ plane is set at the modulus-weighted centroid of the section, also called normal force center [Bauchau and Craig (2009)]). Explicit formulas for $\varepsilon_{1}, \kappa_{2}$, and $\kappa_{3}$ as functions of $\mathbb{C}^{\text {tissue }}, \boldsymbol{N}$ and $\boldsymbol{M}$ are presented in Appendix C. We refer the reader to Bauchau and Craig (2009), Sec. 6.3 and Buenzli et al (2013) for their derivation.

Determination of microscopic stress and strain distributions based on micromechanical homogenisation theory

Bone tissue stiffness $\mathbb{C}^{\text {tissue }}$ is strongly influenced by the tissue's microstructure, in particular its porosity, or equivalently, its bone volume fraction $f_{\mathrm{bm}}$. Bone volume fraction is a microstructural parameter defined at the tissue scale as the volume fraction of bone matrix in the RVE (Figure $1(\mathrm{~d})): f_{\mathrm{bm}}=\mathrm{BV} / \mathrm{TV}=1-$ porosity, where $\mathrm{BV}$ is the volume of bone matrix in the RVE and $\mathrm{TV}$ is the tissue volume, i.e. the total volume of the RVE [Dempster et al (2013)]. In Buenzli et al (2013), we used an explicit power-law relationship $\mathbb{C}_{1111}^{\text {tissue }}\left(f_{\mathrm{bm}}\right) \propto f_{\mathrm{bm}}{ }^{3}$ 
based on experimental relationships between bone stiffness and bone mineral content [Carter and Hayes (1977); Hernandez et al (2001)]. While regression approaches based on power-law relations are able to account for material properties in one principal direction, they are less accurate in estimating material properties in other principal directions.

Here, we follow a different approach taken by Hellmich and colleagues using the framework of continuum micromechanics [Hill $(1963,1965)$; Zaoui $(1997,2002)]$. Mechanically, bone tissue can be considered as a two-phase material: a bone matrix phase ('bm') consisting of mineralised bone matrix, and a vascular phase ('vas') consisting of vascular components, cells, extracellular matrix and other soft tissues present in Haversian canals and in the marrow.

Continuum micromechanics provides a framework to estimate the tissue-scale stiffness tensor $\mathbb{C}^{\text {tissue }}\left(f_{\mathrm{bm}}\right)$ from the microscopic stiffness properties of bone matrix and vascular pores, and assumptions on pore microarchitecture and phase interactions [Hellmich et al (2008)]. The advantage of this approach is to provide (i) accurate three-dimensional estimates of $\mathbb{C}^{\text {tissue }}$ and (ii) estimates of the microscopic stress and strain distributions of the bone matrix without recourse to costly micro-finite element analyses of the tissue microstructure [Fritsch et al (2009)]. Using the concept of continuum micromechanics is justified in bone due to the separation of length scales between the RVE size and the characteristic sizes of the two-phase microstructures [Hellmich et al (2008); Scheiner et al (2013)]. We summarise below the premises upon which this approach is based.

The tissue-scale stress and strain tensors $\sigma^{\text {tissue }}$ and $\varepsilon^{\text {tissue }}$ correspond to spatial averages over the RVE of the microscopic (cellular-scale) stress and strain tensors. Assuming that each phase within the RVE is homogeneous, these spatial averages can be expressed as sums over the phases:

$$
\begin{aligned}
\boldsymbol{\sigma}^{\text {tissue }}(\boldsymbol{r}, t) & \equiv \frac{1}{\mathrm{TV}} \int_{\mathrm{TV}} \boldsymbol{\sigma}^{\text {micro }} \mathrm{d} V=\sum_{k} f_{k} \boldsymbol{\sigma}_{k}^{\text {micro }} \\
\boldsymbol{\varepsilon}^{\text {tissue }}(\boldsymbol{r}, t) & \equiv \frac{1}{\mathrm{TV}} \int_{\mathrm{TV}} \varepsilon^{\text {micro }} \mathrm{d} V=\sum_{k} f_{k} \varepsilon_{k}^{\text {micro }}
\end{aligned}
$$

where $f_{k}(\boldsymbol{r}, t)$ is the volume fraction of phase $k$ ('bm', 'vas'), $\boldsymbol{\sigma}_{k}^{\text {micro }}(\boldsymbol{r}, t)$ and $\boldsymbol{\varepsilon}_{k}^{\text {micro }}(\boldsymbol{r}, t)$ are the microscopic stress and strain tensors in phase $k$. We emphasise that all these quantities still depend on the tissue-scale location $\boldsymbol{r}$ of the RVE in bone, whilst microscopic inhomogeneities are encoded in the phase index $k$. It can be shown that due to the linearity of the constitutive equa-

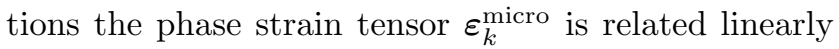

with the tissue-scale strain tensor:

$\varepsilon_{k}^{\text {micro }}=\mathbb{A}_{k}: \varepsilon^{\text {tissue }}$,

where $\mathbb{A}_{k}$ is a fourth-order tensor called the strain concentration tensor [Zaoui (2002); Hellmich et al (2008); Fritsch et al (2009)]. Assuming that Hooke's law also holds for each phase at the microscopic scale, $\sigma_{k}^{\text {micro }}=$ $\mathbb{C}_{k}^{\text {micro }}: \varepsilon_{k}^{\text {micro }}$ (with $\mathbb{C}_{k}^{\text {micro }}$ the stiffness tensor of phase $k$ ), one obtains from Eqs (3) and (5):

$$
\begin{aligned}
\boldsymbol{\sigma}^{\mathrm{tissue}} & =\sum_{k} f_{k} \mathbb{C}_{k}^{\text {micro }}: \varepsilon_{k}^{\text {micro }} \\
& =\left(\sum_{k} f_{k} \mathbb{C}_{k}^{\text {micro }}: \mathbb{A}_{k}\right): \varepsilon^{\text {tissue }} \equiv \mathbb{C}^{\text {tissue }}: \varepsilon^{\text {tissue }}
\end{aligned}
$$

where

$\mathbb{C}^{\text {tissue }}=f_{\mathrm{bm}} \mathbb{C}_{\mathrm{bm}}^{\text {micro }}: \mathbb{A}_{\mathrm{bm}}+f_{\mathrm{vas}} \mathbb{C}_{\mathrm{vas}}^{\text {micro }}: \mathbb{A}_{\mathrm{vas}}$.

Equation (7) provides a relationship between the tissuescale stiffness, $\mathbb{C}^{\text {tissue }}$, and the microscopic properties of the phases composing the tissue, $f_{k}, \mathbb{C}_{k}^{\text {micro }}$, and $\mathbb{A}_{k}$. Because mineral content across bone tissues only varies little on average [Scheiner et al (2013); Fritsch and Hellmich (2007)], $\mathbb{C}_{\mathrm{bm}}^{\text {micro }}$ can be assumed constant and homogeneous, i.e., independent of $\boldsymbol{r}, t$. The elastic mod-

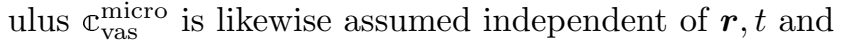
taken as that of water [Scheiner et al (2013)]. Both $\mathbb{C}_{\mathrm{bm}}^{\text {micro }}$ and $\mathbb{C}_{\text {vas }}^{\text {micro }}$ have been measured experimentally, their values are listed in Table 1 . The strain concentration tensors $\mathbb{A}_{k}$ can be estimated by solving so-called matrix-inclusion problems of elasticity homogenisation theory, which use assumptions on phase shape within the RVE and phase interactions [Eshelby (1957); Laws (1977)]. For bone, accurate multi-scale homogenisation schemes were developed and validated experimentally [Hellmich et al (2008); Fritsch et al (2009); Morin and Hellmich (2014)]. These schemes provide explicit expressions for $\mathbb{A}_{k}$ depending on the phase volume fractions $f_{\mathrm{bm}}$ and $f_{\text {vas }}$. Because $f_{\text {vas }}=1-f_{\mathrm{bm}}$, this defines both the $f_{\mathrm{bm}}$ dependence of $\mathbb{C}^{\text {tissue }}$ via Eq. (7), and a method to estimate the strains and stresses in the bone matrix at the microscopic level from those known at the tissue level:

$$
\begin{aligned}
\boldsymbol{\varepsilon}_{\mathrm{bm}}^{\text {micro }}(\boldsymbol{r}, t) & =\mathbb{A}_{\mathrm{bm}}\left(f_{\mathrm{bm}}\right): \boldsymbol{\varepsilon}^{\mathrm{tissue}} \\
\boldsymbol{\sigma}_{\mathrm{bm}}^{\text {micro }}(\boldsymbol{r}, t) & =\mathbb{C}_{\mathrm{bm}}^{\text {micro }}:\left(\mathbb{A}_{\mathrm{bm}}\left(f_{\mathrm{bm}}\right): \varepsilon^{\mathrm{tissue}}\right) \\
& \equiv \mathbb{B}_{\mathrm{bm}}\left(f_{\mathrm{bm}}\right): \boldsymbol{\sigma}^{\mathrm{tissue}}
\end{aligned}
$$

where Hooke's law (1) was used in the last equality in Eq. (9). The stiffness tensor $\mathbb{C}^{\text {tissue }}\left(f_{\mathrm{bm}}\right)$, the strain concentration tensor $\mathbb{A}_{\mathrm{bm}}\left(f_{\mathrm{bm}}\right)$, and the stress concentration tensor $\mathbb{B}_{\mathrm{bm}}\left(f_{\mathrm{bm}}\right)$ can be evaluated numerically at each location $\boldsymbol{r}$ in the femur midshaft cross section 
and each time $t$ based on the value of $f_{\mathrm{bm}}(\boldsymbol{r}, t)$ and the expressions given in Fritsch and Hellmich (2007) and Scheiner et al (2013).

Combined with beam theory, this procedure enables us to completely determine, at each time $t$, the spatial distribution across the femur midshaft of (i) the tissuescale stress and strain tensors, $\sigma^{\text {tissue }}, \varepsilon^{\text {tissue }}$; and (ii) the microscopic stress and strain tensors of bone matrix, $\boldsymbol{\sigma}_{\mathrm{bm}}^{\text {micro }}, \varepsilon_{\mathrm{bm}}^{\text {micro }}$.

In this paper we will consider both the tissue-scale strain energy density (SED), $\Psi^{\text {tissue }}$, and microscopic SED of the bone matrix, $\Psi_{\mathrm{bm}}^{\text {micro }}$, as local mechanical quantities sensed and transduced by bone cells. These SEDs are defined by:

$\Psi^{\text {tissue }}(\boldsymbol{r}, t)=\frac{1}{2} \varepsilon^{\text {tissue }}: \mathbb{C}^{\text {tissue }}: \varepsilon^{\text {tissue }}$,

$\Psi_{\mathrm{bm}}^{\text {micro }}(\boldsymbol{r}, t)=\frac{1}{2} \varepsilon_{\mathrm{bm}}^{\text {micro }}: \mathbb{C}_{\mathrm{bm}}^{\text {micro }}: \varepsilon_{\mathrm{bm}}^{\text {micro }}$.

The SEDs defined in Eqs (10) and (11) will be used to formulate biomechanical regulation in the bone remodelling equations. In the literature, biomechanical regulation is commonly based on the SED since this quantity is scalar and it integrates both microstructural state and loading environment [Fyhrie and Carter (1986); Mullender et al (1994); Ruimerman et al (2005)].

\subsection{Bone tissue remodelling}

The tissue is assumed to be remodelled by a population of active osteoclasts $\left(\mathrm{OC}_{\mathrm{a}}\right)$ and active osteoblasts $\left(\mathrm{OB}_{\mathrm{a}}\right)$. Active osteoclasts are assumed to resorb bone at rate $k_{\text {res }}$ (volume of bone resorbed per cell per unit time). Active osteoblasts are assumed to secrete new bone matrix at rate $k_{\text {form }}$ (volume of bone formed per cell per unit time). These cellular resorption and formation rates are taken to be constant and uniform. However, the bone volume fraction $f_{\mathrm{bm}}(\boldsymbol{r}, t)$ of the tissue may evolve with site-specific rates depending on the balance between the populations of active osteoclasts and active osteoblasts [Martin (1972); Buenzli et al (2013)]:

$\frac{\partial}{\partial t} f_{\mathrm{bm}}(\boldsymbol{r}, t)=k_{\text {form }} \mathrm{OB}_{\mathrm{a}}-k_{\text {res }} \mathrm{OC}_{\mathrm{a}}$.

In Eq. (12), $\mathrm{OC}_{\mathrm{a}}(\boldsymbol{r}, t)$ and $\mathrm{OB}_{\mathrm{a}}(\boldsymbol{r}, t)$ denote the average densities of active osteoclasts and active osteoblasts in the tissue located at $\boldsymbol{r}$ (number of cells in the RVE/TV, Figure $1(\mathrm{~d}))$. The site-specific remodelling rate $\chi_{\mathrm{BV}}(\boldsymbol{r}, t)$ of the tissue at $\boldsymbol{r}$ (also called turnover rate) can be defined as the volume fraction of bone in the RVE that is resorbed and refilled in matched amount per unit time [Parfitt (1983), Sec. II.C.2.c.ii]. This corresponds to the minimum of the volume fraction of bone resorbed per unit time, $k_{\text {res }} \mathrm{OC}_{\mathrm{a}}$, and volume fraction of bone formed per unit time, $k_{\text {form }} \mathrm{OB}_{\mathrm{a}}$ :

$\chi_{\mathrm{BV}}(\boldsymbol{r}, t)=\min \left\{k_{\text {res }} \mathrm{OC}_{\mathrm{a}}, k_{\text {form }} \mathrm{OB}_{\mathrm{a}}\right\}$.

Any imbalance between resorption and formation in Eq. (12) is interpreted as surplus resorption or surplus formation with respect to the baseline of bone properly turned over in Eq. (13).

Equation (12) enables us to track site-specific modifications of the midshaft tissue microstructure through $f_{\mathrm{bm}}(\boldsymbol{r}, t)$, from which stress and strain distributions across the midshaft can be estimated at both the tissue scale and the microscopic, cellular scale, by means of Eqs (34)-(35) and (8)-(11).

\subsection{Bone cell population model}

It remains to specify how the populations of active osteoclasts $\mathrm{OC}_{\mathrm{a}}(\boldsymbol{r}, t)$ and active osteoblasts $\mathrm{OB}_{\mathrm{a}}(\boldsymbol{r}, t)$ evolve in the RVE located at $\boldsymbol{r}$ under mechanobiological, geometrical and biochemical regulations. For this, we use a continuum cell population model based on rate equations, originally developed by Lemaire et al (2004), and later refined and extended by Pivonka and co-workers [Pivonka et al (2008, 2010); Buenzli et al (2012); Pivonka et al (2013); Scheiner et al (2013); Pivonka et al (2012)].

To highlight important biochemical couplings and regulations in osteoclastogenesis and osteoblastogenesis, several differentiation stages of osteoclasts and osteoblasts are considered. These biochemical interactions are mediated by several signalling molecules whose binding kinetics are explicitly considered in the model, such as transforming growth factor $\beta$ (TGF $\beta$ ), receptor-activator nuclear factor $\kappa \mathrm{B}$ (RANK) and associated ligand RANKL, osteoprotegerin (OPG), and parathyroid hormone (PTH). The biochemical network of these couplings and regulations is summarised in Figure 3.

Active osteoclasts $\left(\mathrm{OC}_{\mathrm{a}} \mathrm{s}\right)$ denote cells attached to the bone surface that actively resorb bone matrix. These cells are assumed to differentiate from a pool of osteoclast precursor cells $\left(\mathrm{OC}_{\mathrm{p}} \mathrm{s}\right)$ by the binding of RANKL to the RANK receptor, expressed on $\mathrm{OC}_{\mathrm{p}} \mathrm{s}$, which induces intracellular $\mathrm{NF} \kappa \mathrm{B}$ signalling. Osteoclast precursors are assumed to differentiate from a pool of uncommitted osteoclasts progenitors $\left(\mathrm{OC}_{\mathrm{u}}\right)$, such as haematopoietic stem cells, under the action of macrophage colony stimulating factor (MCSF) and RANKL signalling [Roodman (1999); Martin (2004)].

Active osteoblasts $\left(\mathrm{OB}_{\mathrm{a}} \mathrm{s}\right)$ denote cells at the bone surface that actively deposit new bone matrix. These cells are assumed to differentiate from a pool of osteoblast precursor cells $\left(\mathrm{OB}_{\mathrm{p}} \mathrm{s}\right)$. This activation is inhibited in the presence of $\mathrm{TGF} \beta$. Osteoblast precursors 


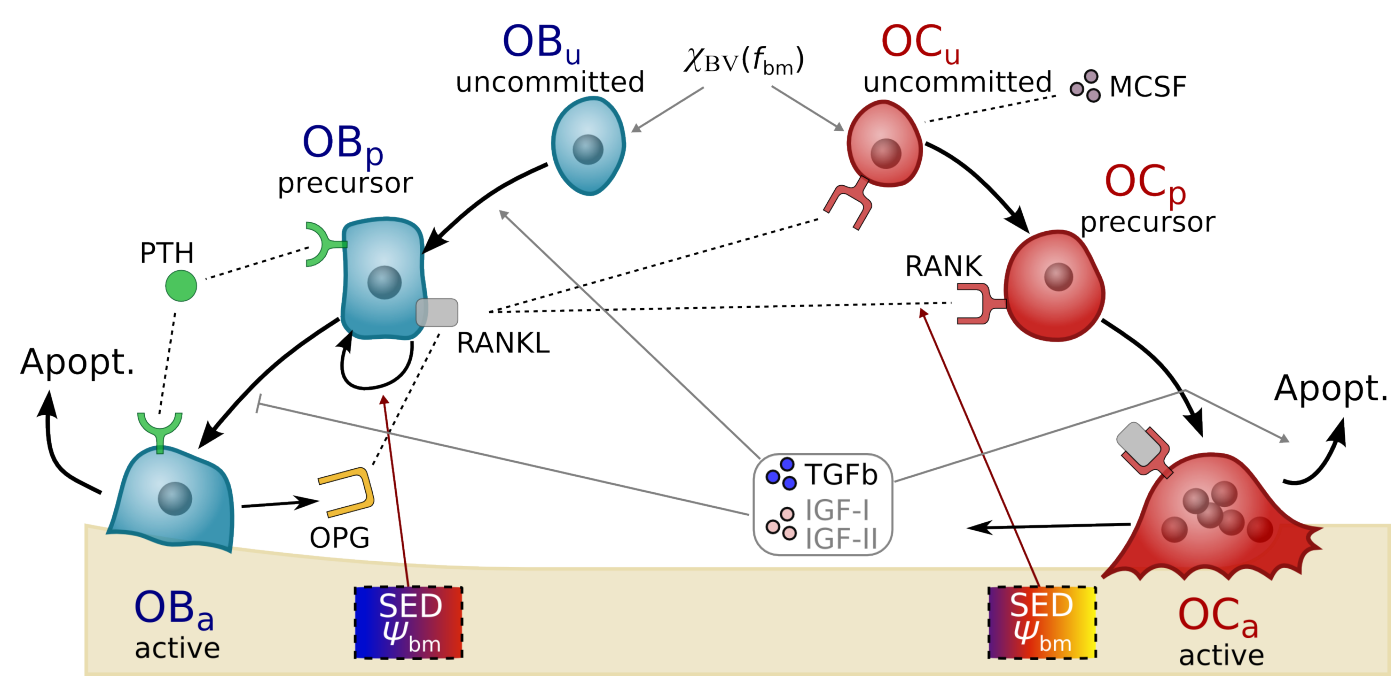

Fig. 3 Proposed cell population model of bone remodelling taking into account several developmental stages of osteoblasts and osteoclasts together with biochemical regulation, biomechanical regulation (via strain energy density, $\Psi$ ) and geometrical regulation (via the turnover function, $\chi_{\mathrm{BV}}\left(f_{\mathrm{bm}}\right)$ ).

are assumed to differentiate from a pool of uncommitted osteoblasts progenitors $\left(\mathrm{OB}_{\mathrm{u}}\right)$, such as mesenchymal stem cells or bone marrow stromal cells, upon TGF $\beta$ signalling [Roodman (1999)].

The rate equations governing the evolution of the tissue-average cell densities are given by:

$$
\begin{aligned}
\frac{\partial}{\partial t} \mathrm{OC}_{\mathrm{p}}(\boldsymbol{r}, t)= & \mathcal{D}_{\mathrm{OC}_{\mathrm{u}}}(\operatorname{MCSF}, \operatorname{RANKL}(\Psi, \mathrm{PTH})) \mathrm{OC}_{\mathrm{u}}\left(f_{\mathrm{bm}}\right) \\
& -\mathcal{D}_{\mathrm{OC}_{\mathrm{p}}}(\operatorname{RANKL}(\Psi, \mathrm{PTH})) \mathrm{OC}_{\mathrm{p}}, \\
\frac{\partial}{\partial t} \mathrm{OC}_{\mathrm{a}}(\boldsymbol{r}, t)= & \mathcal{D}_{\mathrm{OC}_{\mathrm{p}}}(\operatorname{RANKL}(\Psi, \mathrm{PTH})) \mathrm{OC}_{\mathrm{p}} \\
& -\mathcal{A}_{\mathrm{OC}_{\mathrm{a}}}(\operatorname{TGF} \beta) \mathrm{OC}_{\mathrm{a}}, \\
\frac{\partial}{\partial t} \mathrm{OB}_{\mathrm{p}}(\boldsymbol{r}, t)= & \mathcal{D}_{\mathrm{OB}_{\mathrm{u}}}(\operatorname{TGF} \beta) \mathrm{OB}_{\mathrm{u}}\left(f_{\mathrm{bm}}\right)+\mathcal{P}_{\mathrm{OB}_{\mathrm{p}}}(\Psi) \mathrm{OB}_{\mathrm{p}} \\
& -\mathcal{D}_{\mathrm{OB}_{\mathrm{p}}}(\mathrm{TGF} \beta) \mathrm{OB}_{\mathrm{p}}, \\
\frac{\partial}{\partial t} \mathrm{OB}_{\mathrm{a}}(\boldsymbol{r}, t)= & \mathcal{D}_{\mathrm{OB}_{\mathrm{p}}}(\mathrm{TGF} \beta) \mathrm{OB}_{\mathrm{p}} \\
& -A_{\mathrm{OB}_{\mathrm{a}}} \mathrm{OB}_{\mathrm{a}},
\end{aligned}
$$

where $\mathcal{D}_{i}$ is the differentiation rate of cell type $i$ ( $i=$ $\mathrm{OC}_{\mathrm{u}}, \mathrm{OC}_{\mathrm{p}}, \mathrm{OB}_{\mathrm{u}}, \mathrm{OB}_{\mathrm{p}}$ ) modulated by signalling molecules, $\mathcal{A}_{\mathrm{OC}_{\mathrm{a}}}$ is the apoptosis rate of active osteoclasts modulated by TGF $\beta, A_{\mathrm{OB}_{\mathrm{a}}}$ is the (constant) apoptosis rate of active osteoblasts, $\mathcal{P}_{\mathrm{OB}_{\mathrm{p}}}$ is the proliferation rate of osteoblast precursor cells, and $\Psi$ is the strain energy density, taken to be either $\Psi^{\text {tissue }}$ or $\Psi_{\mathrm{bm}}^{\text {micro }}$.

The concentrations of the signalling molecules are governed by rate equations expressing mass action kinetics of receptor-ligand binding reactions. Since time scales involved in cell differentiation and apoptosis are much longer than characteristic times of receptor-ligand binding reactions, the signalling molecule concentrations can be solved for in a quasi-steady state (adiabatic approximation) [Buenzli et al (2012); Pivonka et al (2012)].
Explicit expressions for the signalling molecules concentrations and their modulation of the cell differentiation and apoptosis rates depending on receptor-ligand binding are presented in Appendix A.1 and A.3. Below, we comment in more detail on new features of Eqs (14)(17) that are included to model the geometrical and biomechanical feedbacks on bone cell populations.

\section{Geometrical feedback and turnover rate}

The local availability of bone surface to osteoclasts and osteoblasts is an important factor determining the propensity of initiating new bone remodelling events [Martin (1972); Buenzli et al (2013)]. A remarkable relationship between the density of bone surface, $\mathrm{S}_{\mathrm{V}}$, and bone volume fraction, $f_{\mathrm{bm}}$, has been exhibited in bone tissues across wide ranges of porosities [Martin (1984); Fyhrie and Kimura (1999); Lerebours et al (2015)]. This property is particularly interesting from a computational modelling perspective as it enables to track microstructural changes of bone tissues through the evolution of bone volume fraction only.

In femur midshafts, bone tissue is usually compact, the bone volume fraction is high. However, during bone loss, bone volume fraction tends to decrease in the endocortical region. Due to the fact that $f_{\mathrm{bm}}$ reaches values similar to trabecular bone volume fractions, this tissue has been called "trabecularised" cortical bone [Zebaze et al (2010)]. Here, we treat compact and porous tissues differently in terms of bone turnover rates [Parfitt (1983); Martin et al (1998)]. Different turnover rates in Eq. (13) can be achieved by assuming that $\mathrm{OB}_{\mathrm{u}}$ and $\mathrm{OC}_{\mathrm{u}}$ are functions of the bone matrix volume fraction, 
(a)

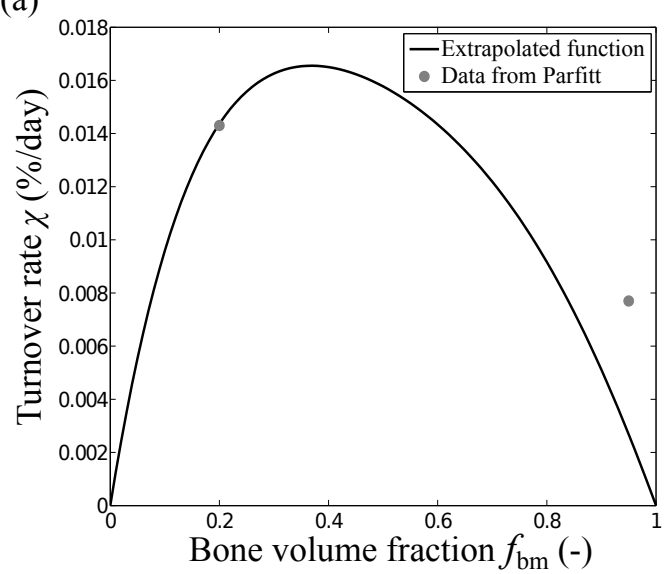

(b)

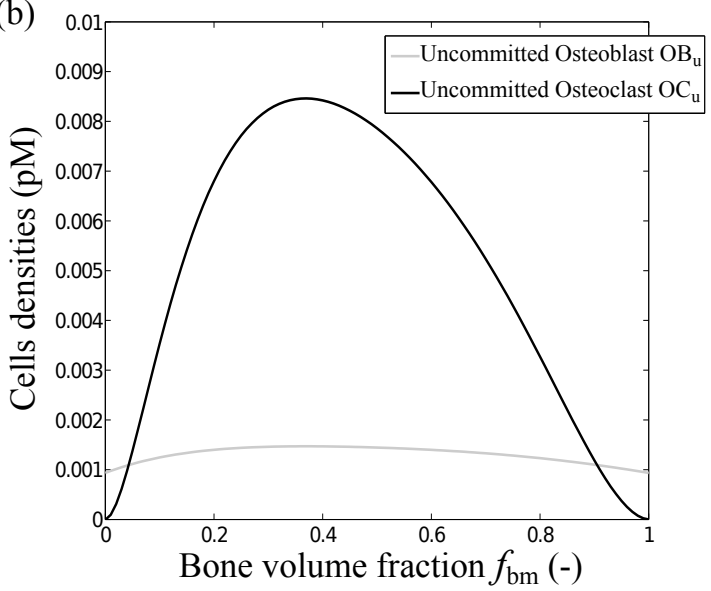

Fig. 4 (a) Plot of the phenomenological relationship $\chi_{\mathrm{BV}}\left(f_{\mathrm{bm}}\right)$ between turnover rate and bone volume fraction assumed in the model, the grey data points are the ones given by Parfitt [Parfitt (1983)]. (b) Dependence of $\mathrm{OC}_{\mathrm{u}}$ and $\mathrm{OB}_{\mathrm{u}}$ upon $f_{\mathrm{bm}}$ assumed in the bone cell population model.

$f_{\mathrm{bm}}$, which introduces a dependence of the active bone cell populations, $\mathrm{OC}_{\mathrm{a}}$ and $\mathrm{OB}_{\mathrm{a}}$, upon $f_{\mathrm{bm}}$ via Eqs. (14)(17). This dependence may account both for the influence of bone surface availability on turnover rate via the $\mathrm{S}_{\mathrm{V}}\left(f_{\mathrm{bm}}\right)$ relation, and for influences of the biochemical microenvironment between cortical bone and trabecularised bone.

Few experimental data explicitly associate turnover rate with microstructure. However, since the relationship $\mathrm{S}_{\mathrm{V}}\left(f_{\mathrm{bm}}\right)$ is well established experimentally, it can be expected that a phenomenological relationship, $\chi_{\mathrm{BV}}\left(f_{\mathrm{bm}}\right)$, associating bone turnover with bone volume fraction is well-defined. Parfitt reports that cortical bone of average bone volume fraction 0.95 has a turnover rate of 0.115 $\mathrm{cm}^{3} /$ day, corresponding to $\chi_{\mathrm{BV}}(0.95) \approx 0.77 \cdot 10^{-4} /$ day with $\mathrm{TV}^{\text {cort }}=1.5 \cdot 10^{6} \mathrm{~mm}^{3}$. Moreover, he states that trabecular bone of average bone volume fraction 0.20 has a turnover rate of $0.25 \mathrm{~cm}^{3} /$ day, corresponding to $\chi_{\mathrm{BV}}(0.20) \approx 1.43 \cdot 10^{-4} /$ day with $\mathrm{TV}^{\text {trab }}=1.75 \cdot 10^{6} \mathrm{~mm}^{3}$ [Parfitt (1983), Table 1 and Table 7]. We take for $\chi_{\mathrm{BV}}\left(f_{\mathrm{bm}}\right)$ a dome-shaped function following Parfitt's reported values and having a zero turnover rate for $f_{\mathrm{bm}}$ equal to 0 and 1 (Figure $4(\mathrm{a})$ ). The maximum of bone turnover is assumed to occur at $f_{\mathrm{bm}}=0.35$, corresponding to typical trabecular or trabecularised bone microstructures. These types of microstructures are expected to remodel at the highest rates due to the proximity of precursor cells in the marrow and the large availability of bone surface.

The functions $\mathrm{OC}_{\mathrm{u}}\left(f_{\mathrm{bm}}\right)$ and $\mathrm{OB}_{\mathrm{u}}\left(f_{\mathrm{bm}}\right)$ are determined such that the turnover rate obtained from the cell population model in a normal healthy state with balanced remodelling, matches the phenomenological relationship $\chi_{\mathrm{BV}}\left(f_{\mathrm{bm}}\right)$. From Eqs (12) and (13), the bal- anced steady-state condition and the remodelling rate condition impose the constraints

$$
\begin{aligned}
\chi_{\mathrm{BV}}\left(f_{\mathrm{bm}}\right) & =k_{\text {form }} \overline{\mathrm{OB}_{\mathrm{a}}}\left(\mathrm{OC}_{\mathrm{u}}\left(f_{\mathrm{bm}}\right), \mathrm{OB}_{\mathrm{u}}\left(f_{\mathrm{bm}}\right)\right) \\
& =k_{\text {res }} \overline{\mathrm{OC}_{\mathrm{a}}}\left(\mathrm{OC}_{\mathrm{u}}\left(f_{\mathrm{bm}}\right), \mathrm{OB}_{\mathrm{u}}\left(f_{\mathrm{bm}}\right)\right)
\end{aligned}
$$

at each value of $f_{\mathrm{bm}} \in[0,1]$, where the bar indicates steady-state values of the cell density variables. These two constraints were solved numerically with the turnover rate function $\chi_{\mathrm{BV}}\left(f_{\mathrm{bm}}\right)$ reported in Figure $4(\mathrm{a})$ by using a trust-region dogleg method. The functions $\mathrm{OC}_{\mathrm{u}}\left(f_{\mathrm{bm}}\right)$ and $\mathrm{OB}_{\mathrm{u}}\left(f_{\mathrm{bm}}\right)$ obtained by this procedure are shown in Figure 4(b). These functions are used as input in Eqs (14)-(17) in all our simulations. This ensures that in steady state, each RVE of the midshaft cross section located at $\boldsymbol{r}$ remodels at rate $\chi_{\mathrm{BV}}\left(f_{\mathrm{bm}}(\boldsymbol{r})\right)$ without changing its bone volume fraction. The functions $\mathrm{OC}_{\mathrm{u}}\left(f_{\mathrm{bm}}\right)$ and $\mathrm{OB}_{\mathrm{u}}\left(f_{\mathrm{bm}}\right)$ are assumed to hold unaffected in the various deregulating circumstances considered later on (i.e., osteoporosis and altered mechanical loading).

The explicit calibration of the cell population model, Eqs (14)-(17), to site-specific tissue remodelling rates is a significant novelty compared to our previous temporal model [Pivonka et al (2013); Scheiner et al (2013)]. This modification was made necessary to consistently describe the site-specific evolution of bone in the spatiotemporal framework of Buenzli et al (2013) whilst retaining a cell population model that includes biochemical regulations.

\section{Mechanical feedback and initial bone microstructure sta- bility}

A mechanical feedback is included in the cell population model such that underloaded regions of bone promote os- 
teoclastogenesis and overloaded regions of bone promote osteoblastogenesis [Frost $(1987,2003)]$. These responses are viewed as consequences of biochemical signals transduced from a mechanical stimulus sensed by osteocytes [Bonewald (2011)]. Osteocytes are known to express RANKL, which regulates osteoclast generation, and sclerostin, which regulates osteoblast generation via Wnt signalling [Bonewald and Johnson (2008)]. Following Scheiner et al (2013), the resorptive response of the mechanical feedback is assumed to act by an increase in the microenvironmental concentration of RANKL, whereas its formative response is assumed to act by an increase in the proliferation rate of osteoblast precursors.

The exact nature of the mechanical stimulus sensed by osteocytes is still a matter of debate. It may include lacuno-canalicular extracellular fluid shear stress on the osteocyte cell membrane, extracellular fluid pressure, streaming potentials and direct deformations of the osteocyte body induced by bone matrix strains [Knothe Tate (2003); Bonewald and Johnson (2008); Bonewald (2011)]. Due to the extensive network of osteocyte connections in bone [Buenzli and Sims (2015)], average bone matrix strains at a higher scale may also be sensed by the osteocyte network. Below, we assume that the mechanical stimulus to the bone cell population model is described by a local strain energy density, $\Psi(\boldsymbol{r}, t)$. This strain energy density will be taken to be either the microscopic, cellular-scale strain energy density of bone matrix, $\Psi_{\mathrm{bm}}^{\text {micro }}(\boldsymbol{r}, t)$, or the average tissue-scale strain energy density, $\Psi^{\text {tissue }}(\boldsymbol{r}, t)$, defined respectively in Eqs (11) and (10).

To predict with our model the evolution of a real scan of midshaft femur under various deregulating circumstances, it is important to assume that the bone scan represents a stable state initially in absence of any deregulation. In particular, this initial bone state is assumed mechanically optimal. This can be ensured by choosing the local mechanical stimulus acting onto the bone cells, $\mu(\boldsymbol{r}, t)$, as a normalised difference between the current SED and the SED of the inital bone microstructure $\Psi(\boldsymbol{r}, 0)$ :

$\mu(\boldsymbol{r}, t)=\frac{\Psi(\boldsymbol{r}, t)-\Psi(\boldsymbol{r}, 0)}{\Psi(\boldsymbol{r}, 0)+K}$

The normalisation by $\Psi(\boldsymbol{r}, 0)$ in the denominator in Eq. (20) ensures that the mechanical stimulus is not over-emphasised away from the neutral axis where strain energy density takes high values. The small positive constant $K=1 \cdot 10^{-6} \mathrm{GPa}$ is added to keep mechanical stimulus well defined near the neutral axis where $\Psi(\boldsymbol{r}, 0) \approx 0$ (see also Discussion section 4$)$.
When negative, $\mu(\boldsymbol{r}, t)$ in Eq. (20) is assumed to promote $\beta_{\mathrm{RANKL}}^{\text {mech }}$, the production rate of RANKL:

$\beta_{\mathrm{RANKL}}^{\text {mech }}(\Psi)= \begin{cases}-\kappa \cdot \mu(\boldsymbol{r}, t), & \text { if } \mu(\boldsymbol{r}, t) \leq 0 \\ 0, & \text { if } \mu(\boldsymbol{r}, t)>0\end{cases}$

where $\kappa$ is a parameter describing the strength of the biomechanical transduction (see section 2.6). This results in increased RANKL signalling in underloaded conditions (see Eq. (28) in Appendix), and so in increased osteoclast generation in Eqs (14)-(15).

When positive, $\mu(\boldsymbol{r}, t)$ in Eq. (20) is assumed to promote $\mathcal{P}_{\mathrm{OB}_{\mathrm{p}}}$, the proliferation rate of pre-osteoblasts in Eq. (16):

$\mathcal{P}_{\mathrm{OB}_{\mathrm{p}}}(\Psi)=P_{\mathrm{OB}_{\mathrm{p}}}+ \begin{cases}0, & \text { if } \mu(\boldsymbol{r}, t) \leq 0 \\ P_{\mathrm{OB}_{\mathrm{p}}} \cdot \lambda \cdot \mu(\boldsymbol{r}, t), & \text { if } 0<\mu(\boldsymbol{r}, t)<\frac{1}{\lambda} \\ P_{\mathrm{OB}_{\mathrm{p}}}, & \text { if } \mu(\boldsymbol{r}, t) \geq \frac{1}{\lambda}\end{cases}$

where $\lambda$ is a parameter describing the strength of the biomechanical transduction. The first term in (22) accounts for a transit-amplifying stage of osteoblast differentiation occurring in absence of mechanical stimulation [Buenzli et al (2012)]. The proliferation rate is assumed to saturate to the value $\mathcal{P}_{\mathrm{OB}_{\mathrm{p}}}=2 P_{\mathrm{OB}_{\mathrm{p}}}$ in highly overloaded situations to ensure the stability of the population of $\mathrm{OB}_{\mathrm{p}} \mathrm{s}$ [Buenzli et al (2012); Scheiner et al (2013)].

A similar type of mechanical feedback was implemented in purely temporal settings in Scheiner et al (2013). The initial strain energy density distribution, $\Psi(\boldsymbol{r}, 0)$, is calculated from Eqs (10)-(11) and from the initial bone volume fraction distribution, $f_{\mathrm{bm}}(\boldsymbol{r}, 0)$, determined on the bone scan (described in the next section).

\subsection{Initial distribution of bone volume fraction from microradiographs}

The initial microstructural state of the midshaft bone cross section can be derived from high-resolution bone scans such as micro-computed tomography (microCT) scans or microradiographs. Since Haversian canals have an average diameter of about $40 \mu \mathrm{m}$, at least $10 \mu \mathrm{m}$ resolution is required to evaluate intracortical bone volume fractions with sufficient accuracy.

In the simulations presented in Section 3, we used the microradiograph represented in Figure 5(a) where the pixel size is $7 \mu \mathrm{m}$. The femur sample was collected from a 21-year-old subject. The microradiograph was digitised and binarised by a thresholding operation based on pixel grey level. Bone matrix is assigned the value 1 
(a) Microradiograph

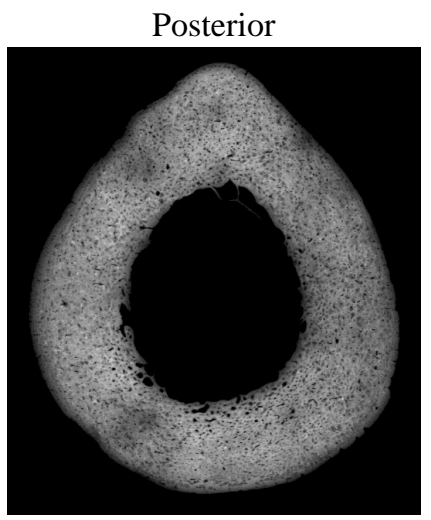

Anterior (b) Binarised image

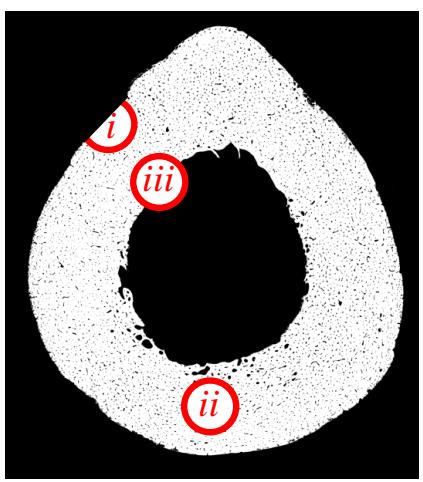

(c) Bone volume fraction distribution

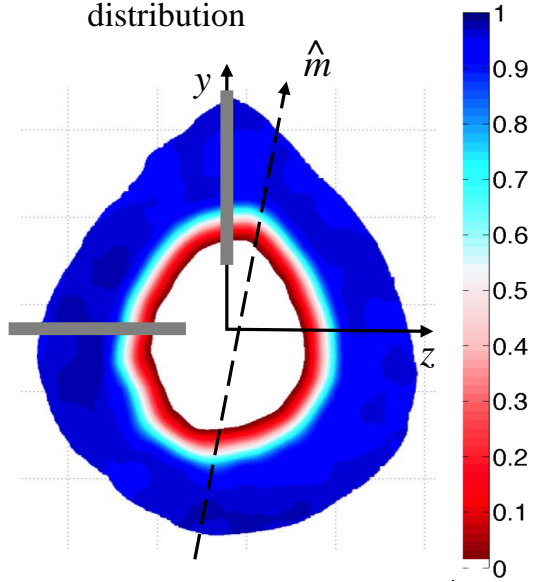

Fig. 5 (a) Microradiograph of a midshaft femur cross section (courtesy of C. David L. Thomas and John G. Clement, Melbourne Femur Collection). (b) Binarisation of the microradiograph and determination of the local $f_{\mathrm{bm}}$ values: (i) at the periosteal region, (ii) in the intracortical region, and (iii) at the endosteal region; (c) Bone volume fraction distribution extracted from the radiograph and interpolated. The dashed line represents the location of the neutral axis. The origin of the coordinate system $(y, z)$ is taken at the normal force center, NC. The grey lines are the $10 \mathrm{~mm}$ along which we are studying the evolution of the model in the Results Section.

irrespective of the degree of mineralisation, and intracortical pores are assigned the value 0 . The distribution of the bone volume fraction, $f_{\mathrm{bm}}(\boldsymbol{r}, 0)$, across the midshaft was determined by calculating the volume of bone matrix in a disk of $2 \mathrm{~mm}$ diameter, centred at each pixel of the binarised image and divided by the disk's area. For the points near the periosteal surface, only the portion of the disk contained into the subperiosteal area was used for this calculation (see Figure 5(b)). The discrete values of $f_{\mathrm{bm}}$ defined at each pixel contained in the subperiosteal region were then interpolated into a continuous function, $f_{\mathrm{bm}}(\boldsymbol{r}, 0)$, using Matlab's 2D cubic interpolation procedure. The result is shown in Figure 5(c). A similar exclusion was not performed at the endosteal surface since this surface is less well defined, in opposition to the periosteal surface, due to the presence of 'trabecular-like structures. Bone matrix volume fractions near the endosteal surface are averages of intracortical bone regions and regions in the bone marrow cavity.

\subsection{Numerical simulations}

The multiscale mechanobiological model of bone remodelling presented in this paper is governed by a coupled system of (i) distributed ODEs describing the evolution of bone cell populations at each location $\boldsymbol{r}$ in the midshaft femur (Eqs (14)-(17)); and (ii) non-local and tensorial algebraic equations determining the mechanical state of the tissue RVE at $\boldsymbol{r}$, both at the tissue scale and at the microscopic scale (Eqs (2)-(11)). The model is initialised with a bone volume fraction distribution across the midshaft femur deduced from high-resolution bone scans (Figure 5(a)) and with steady-state populations of cells fulfilling the site-specific turnover rate conditions Eqs. (18)-(19). This initial state is thereby constructed to be a steady state of the model, in which the biochemical, geometrical and mechanobiological regulations of resorption and formation are balanced.

To solve this non-local spatio-temporal problem numerically, we use a staggered iteration scheme in which we first solve the mechanical problem (i.e., tissue-scale SED and microscopic SED) assuming constant material properties, and then solve the bone cell population model and evolve the bone volume fraction at each location $\boldsymbol{r}$ of the femur midshaft assuming constant mechanical feedback for a duration $\Delta \mathrm{t}$. After $\Delta \mathrm{t}$, the mechanical problem is recalculated based on the updated bone volume fraction distribution, $f_{\mathrm{bm}}(\boldsymbol{r}, \mathrm{t}+\Delta \mathrm{t})$, and this procedure is iterated. The ODEs are solved using a standard stiff ODE solver (Matlab, ode15s). The spatial discretisation is a regular grid with steps $\Delta y=\Delta z=0.8 \mathrm{~mm}$. Due to the separation of time scales between changes in the local mechanical environment (years) and changes in bone cell populations (days), the mechanical stimulus requires updating after durations $\Delta \mathrm{t}=2$ years. The accuracy of the numerical results depending on $\Delta \mathrm{t}$ is studied in Appendix B. 
(a) Osteoporosis simulation via PTH infusion

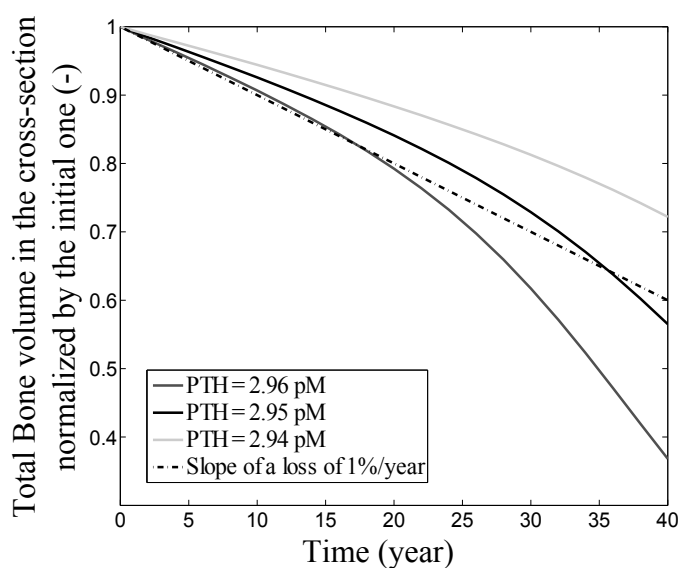

(b) Spaceflight simulation

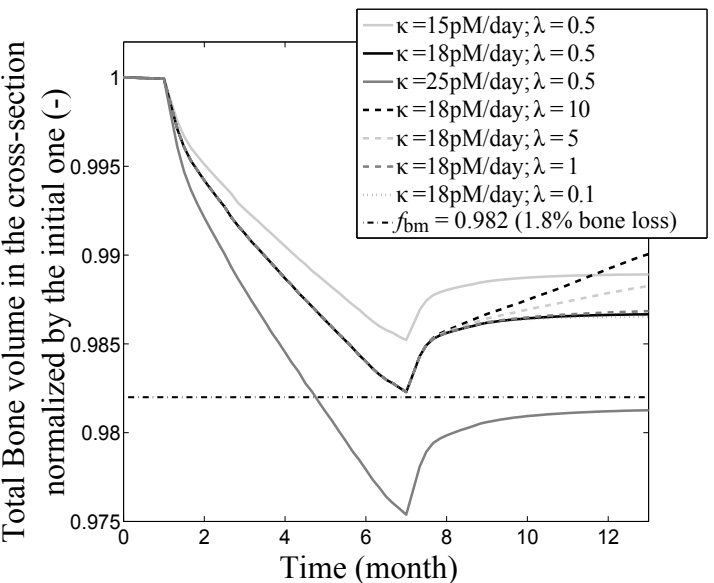

Fig. 6 (a) Evolution of the total bone mass in the cross section with time while simulating osteoporosis: calibration of the PTH infusion. Osteoporosis is characterised by a bone loss of 1\%/year [Parfitt and Chir (1987); Nordin et al (1988); Szulc et al (2006)]. (b) Evolution of the total bone mass in the cross section with time while simulating a spaceflight mission: calibration of the mechanical parameters, $\lambda$ and $\kappa$.

\subsection{Model calibration}

The model presented in this paper contains: (i) biomechanical parameters associated with the estimation of $\Psi(\boldsymbol{r}, t)$, and (ii) parameters associated with the bone cell population model. Biomechanical parameters as well as biochemical parameters were determined and validated in other studies [Scheiner et al (2013); Pivonka et al (2013, 2008); Buenzli et al (2012)] (Table 1). Here we calibrate the newly introduced parameters: (a) mechanical coupling parameters $\lambda$ and $\kappa$ (Eqs (21) and (22)), and (b) biochemical parameters related to the simulation of osteoporosis.

Calibration of the hormonal deregulation for osteoporosis simulation

In our previous temporal model [Scheiner et al (2013)], osteoporosis was modelled by an increase in systemic PTH together with a reduction in the biomechanical transduction parameters: $\lambda$ and $\kappa$. In this paper, we simulate age-related bone loss using a single parameter perturbation, i.e., an increase in systemic PTH concentration. This increase is calibrated so as to obtain a loss of total bone cross-sectional area in the femur midshaft of $1 \%$ per year ${ }^{2}$ [Parfitt and Chir (1987); Nordin et al (1988); Szulc et al (2006)]. The total bone cross-sectional area is defined by the integral of $f_{\mathrm{bm}}(\boldsymbol{r}, t)$ over the midshaft cross section. In the model, a rate of bone loss of

2 The calibration is performed without mechanical adaptation (i.e. setting $\lambda=0$ and $\kappa=0$ in Eqs (21) and (22)) in order to compare both mechanical feedbacks in a more consistent way.
$1 \% /$ year was obtained by an increase in systemic concentration of PTH from $2.907 \mathrm{pM}$ to $2.954 \mathrm{pM}(1.62 \%$ increase) (see Figure 6(a)).

\section{Calibration of mechanobiological feedback}

The rate of change in bone mass due to mechanical feedback is determined in the model by the biomechanical transduction parameters $\lambda$ (in Eq. (22)) and $\kappa$ (in Eq. (21)). To calibrate these parameters, we used data gathered from mechanical disuse and re-use experiments. It has been shown that cosmonauts undertaking long mission space flights lose bone mass at a rate of approximately $0.3 \%$ per month [Vico et al (2000)]. This microgravity-induced bone loss is only slowly recovered after return to Earth. No significant bone gain is observed after 6 month exposure to normal gravity on Earth [Vico et al (2000); Collet et al (1997)].

In our multiscale model, microgravity is simulated as a $80 \%$ reduction of the normal mechanical loads experienced by the femur, i.e., $\boldsymbol{N}_{\text {microgravity }}=0.2 \mathrm{~N}$ and $\boldsymbol{M}_{\text {microgravity }}=0.2 \boldsymbol{M}$. Based on these reduced loads, the parameter $\kappa$ has been calibrated such that $1.8 \%$ of total bone cross-sectional area is lost after 6 months. We found such rate of loss with $\kappa=18 \mathrm{pM} /$ day when the mechanical stimulus is based on the microscopic $\mathrm{SED}, \Psi_{\mathrm{bm}}^{\text {micro }}(\boldsymbol{r}, t)$ (see Figure $6(\mathrm{~b})$ ), and $\kappa=19 \mathrm{pM} /$ day when the mechanical stimulus is based on the tissuescale SED, $\Psi^{\text {tissue }}(\boldsymbol{r}, t)$. After return to Earth, rates of bone recovery are too low to be detected after 6 months [Collet et al (1997)]. We performed a parametric study investigating various strengths of $\lambda$. Using parameter values of $\lambda>1$ in our model results in significant bone 
gain after 6 months, while $\lambda \leq 1$ results in small bone gain. Based on these results we use $\lambda=0.5$ for both the microscopic and tissue-scale mechanical stimuli.

\section{Results}

In this section we present numerical simulations of the evolution of the midshaft femur cross section subjected to either: (i) changes in mechanical environment (Section 3.1), or (ii) hormonal deregulation simulating osteoporosis (Section 3.2). We also investigate how sitespecific bone loss may depend on whether mechanical stimulus is sensed at the microscopic, cellular scale, or at the tissue scale.

\subsection{Bone loss due to mechanical disuse}

Figure 7(a) represents site-specific changes of the femur midshaft cross section simulated by the model assuming a $80 \%$ reduction in the normal mechanical loading. This reduction in mechanical loading may represent microgravity in long spaceflight missions (see Section 2.6) or prolonged bed rest. The Figure depicts the difference between the bone volume fraction distribution after 6 months of mechanical disuse and the initial bone volume fraction. It can be seen that bone loss is site-specific with more bone loss occurring near the endosteal surface. Close to the neutral axis, only limited loss of bone is observed.

\subsection{Simulation of osteoporosis due to hormonal deregulation}

Figures 7(b) and (c) represent the site-specific changes of the midshaft cross section that occur after 40 years of simulated osteoporosis when the mechanical feedback acting onto the bone cell population model is based on the microscopic SED. Figure 7(b) depicts the difference between the $f_{\mathrm{bm}}$ distribution at the end of the simulation and the initial distribution. Figure 7(c) depicts the $f_{\mathrm{bm}}$ distribution at the end of the simulation. Bone loss occurs everywhere in the cross section except at the medial and lateral sides. The loss is site-specific with higher rates of loss in the endocortical region and around the neutral axis, close to the antero-posterior axis. This pattern of bone loss is consistent with the high porosity commonly observed in these regions in osteoporotic subjects (Figure 7(d), arrows). The simulation exhibits a sharp transition between a very porous endocortical region and a dense intracortical region towards the periosteum. Although perhaps less pronounced, such a transition is also observed in the microradiograph of Figure 7(d) (dashed lines). In contrast to the osteoporosis simulation, the simulation of mechanical disuse (Figure $7(\mathrm{a})$ ) shows that bone was lost all over the cross section, with little change around the neutral axis. In both simulations, bone was lost predominantly in the endocortical region.

In Figure 8, we show how the distributions of the following quantities evolved along the $y$ - and the $z$-axes during the simulation of osteoporosis: (a) the bone volume fraction, (b) the microscopic mechanical stimulus, $\mu_{\mathrm{bm}}^{\text {micro }}$, used as mechanical stimulus in this simulation, (c) the tissue-scale mechanical stimulus, $\mu^{\text {tissue }}$, not used as mechanical stimulus in this simulation, and (d) the turnover rate. Along both axes, the regions in which bone volume fraction transitions from low to high (3 $<y<6 \mathrm{~mm}$ and $-7<z<-5 \mathrm{~mm}$ ) are resorbed at higher rate, due to the higher values of $\chi_{\mathrm{BV}}$ in these regions (Figure $8(\mathrm{~d})$ ). As time progresses, bone volume fraction is strongly reduced in the endocortical region, leading to an expansion of the marrow space and a reduction in cortical wall width. This is accompanied by a shift of the maximum of $\chi_{\mathrm{BV}}$ towards the periosteum. Along the $y$-axis (near the neutral axis), bone is lost at a high rate not only in the endocortical region but also near the periosteum, as can be seen by the gradual increase in turnover rate in the whole cortical width (Figure $8(\mathrm{~d})$ ). In contrast, along the $z$-axis, bone is lost at a high rate only at the endosteum where turnover rate maintains a well-defined peak. The intracortical region $(z<-7 \mathrm{~mm})$ is preserved even after 40 years of simulated osteoporosis.

\section{Microscopic vs tissue-scale mechanical stimulus}

Comparing Figures 8(b) and (c), we can observe that the values of the mechanical adaptation stimuli are strongly dependent on the length scale at which they are calculated, i.e. tissue scale or microscopic scale. Along the $z$-axis, $\mu_{\mathrm{bm}}^{\text {micro }}$ is always positive (Figure $8(\mathrm{~b})$ ), whereas, $\mu^{\text {tissue }}$ takes negative values in the endocortical region (Figure 8(c)). Regions with high values of $\mu_{\mathrm{bm}}^{\text {micro }}$ and positive values of $\mu^{\text {tissue }}$ correlate with regions where the bone matrix is preserved. Regions with low values of $\mu_{\mathrm{bm}}^{\text {micro }}$ and negative values of $\mu^{\text {tissue }}$ correlate with regions where the bone matrix is resorbed. The Figures also show a qualitative and quantitative difference in mechanical stimuli $\mu_{\mathrm{bm}}^{\text {micro }}$ and $\mu^{\text {tissue }}$ between the $y$ - and $z$-axes. The mechanical stimulus is asymmetric between the antero-posterior axis and lateral-medial axis due to the assumed bending loading state. Along the $y$-axis, no important variation can be observed between endocortical and periosteal regions. Along the $z$-axis, both 
(a) After spaceflight: $f_{\mathrm{bm}}(t=6 \mathrm{~m})-f_{\mathrm{bm}}(t=0)$

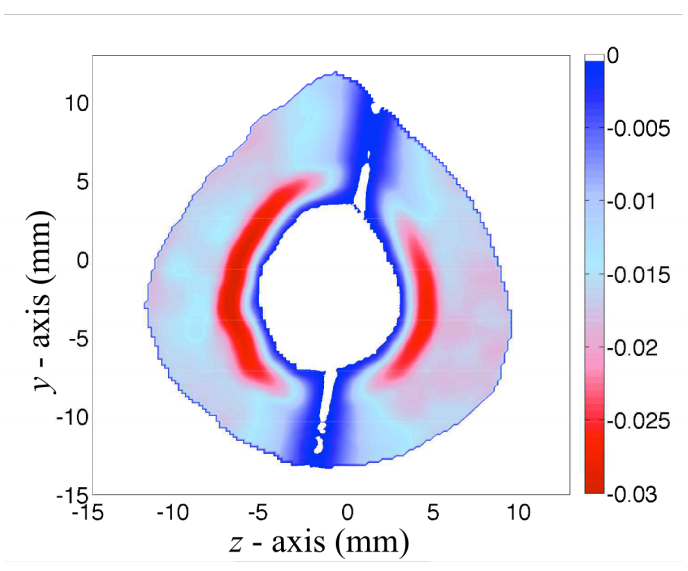

(c) After 40 years of simulated osteoporosis

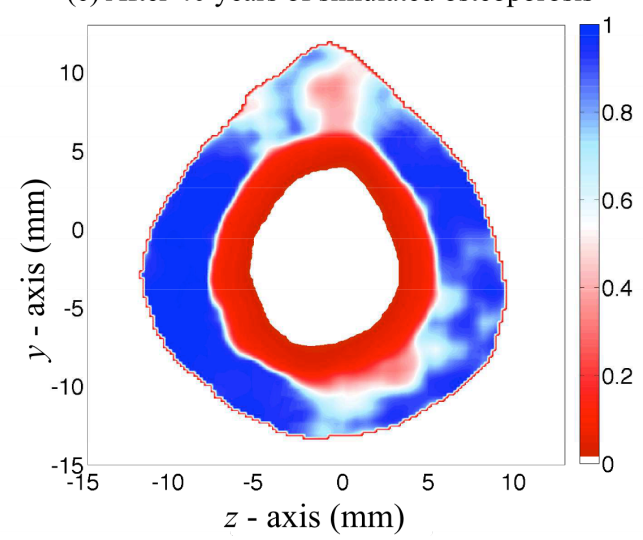

(b) After simulated osteoporosis: $f_{\mathrm{bm}}(t=40 \mathrm{y})-f_{\mathrm{bm}}(t=0)$

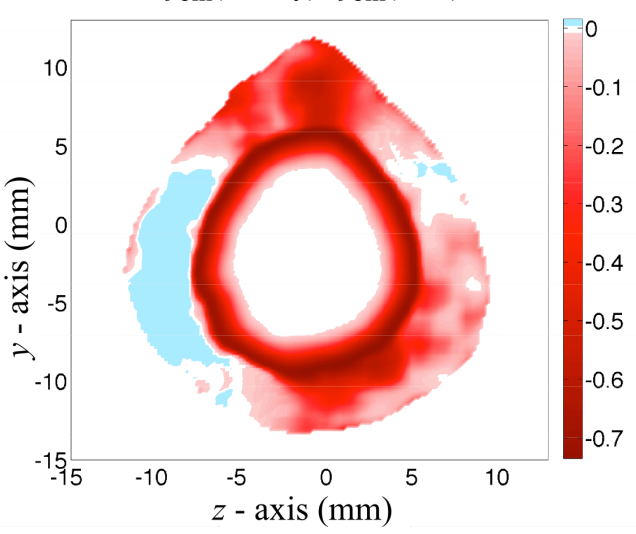

(d) Microradiograph of a 89 yo individual

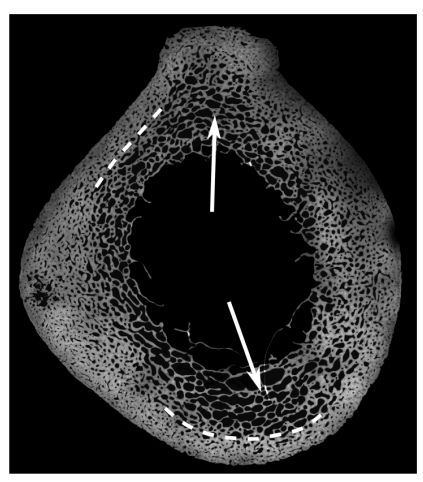

Fig. 7 (a) Difference between the bone volume fraction distribution in the cross section after a 6-months spaceflight mission with the initial distribution. (b) Difference between the bone volume fraction distribution in the cross section after a 40-years of simulated osteoporosis with the initial distribution. (c) Bone Volume Fraction distribution in the cross section after 40 years of simulated osteoporosis. (d) Microradiograph of a human femur cross section from an 89 years old individual. The dashed lines highlight regions with sharp transition between porous and compact tissue. The arrows point out regions with high porosity along the antero-posterior axis.

stimuli exhibit much lower values in the endocortical region than at the periosteum or in the marrow cavity. We note that the mechanical stimulu are not zero in the marrow even when $f_{\mathrm{bm}}=0$ due to the assumed vascular stiffness.

Figure 9 compares the evolution of bone volume fraction during simulated osteoporosis when the mechanical stimulus acting onto the bone cells is either (i) absent, (ii) based on the microscopic mechanical stimulus, $\mu_{\mathrm{bm}}^{\text {micro }}$, or (iii) based on the tissue-scale mechanical stimulus, $\mu^{\text {tissue }} .^{3}$ All cases exhibit strong endocortical bone loss with little difference in the expansion rate of the medullary cavity. A slightly steeper endosteal wall is created along the $z$-axis during the simulation using

3 For the simulation in case (iii), the mechanical transduction strength parameters are: $\kappa=19 \mathrm{pM} /$ day and $\lambda=0.5$, calibrated with the tissue-scale mechanical stimulus while simulating spaceflight. tissue-scale mechanical stimulus, and a region with very low bone volume fraction $\left(f_{\mathrm{bm}} \simeq 0.1\right)$ is preserved in the medullary cavity during the simulation with microscopic mechanical stimulus. Intracortical bone towards the periosteum is preserved along the $z$-axis by both mechanical stimuli, but it is resorbed more strongly along the $y$-axis in the simulation with tissue-scale mechanical stimulus.

\section{Discussion}

\section{Endocortical bone loss}

The loss of endocortical bone, with its associated expansion of the marrow cavity and cortical wall thinning, is a trait common to several bone disorders and deregulations of remodelling. It is observed in osteoporosis 

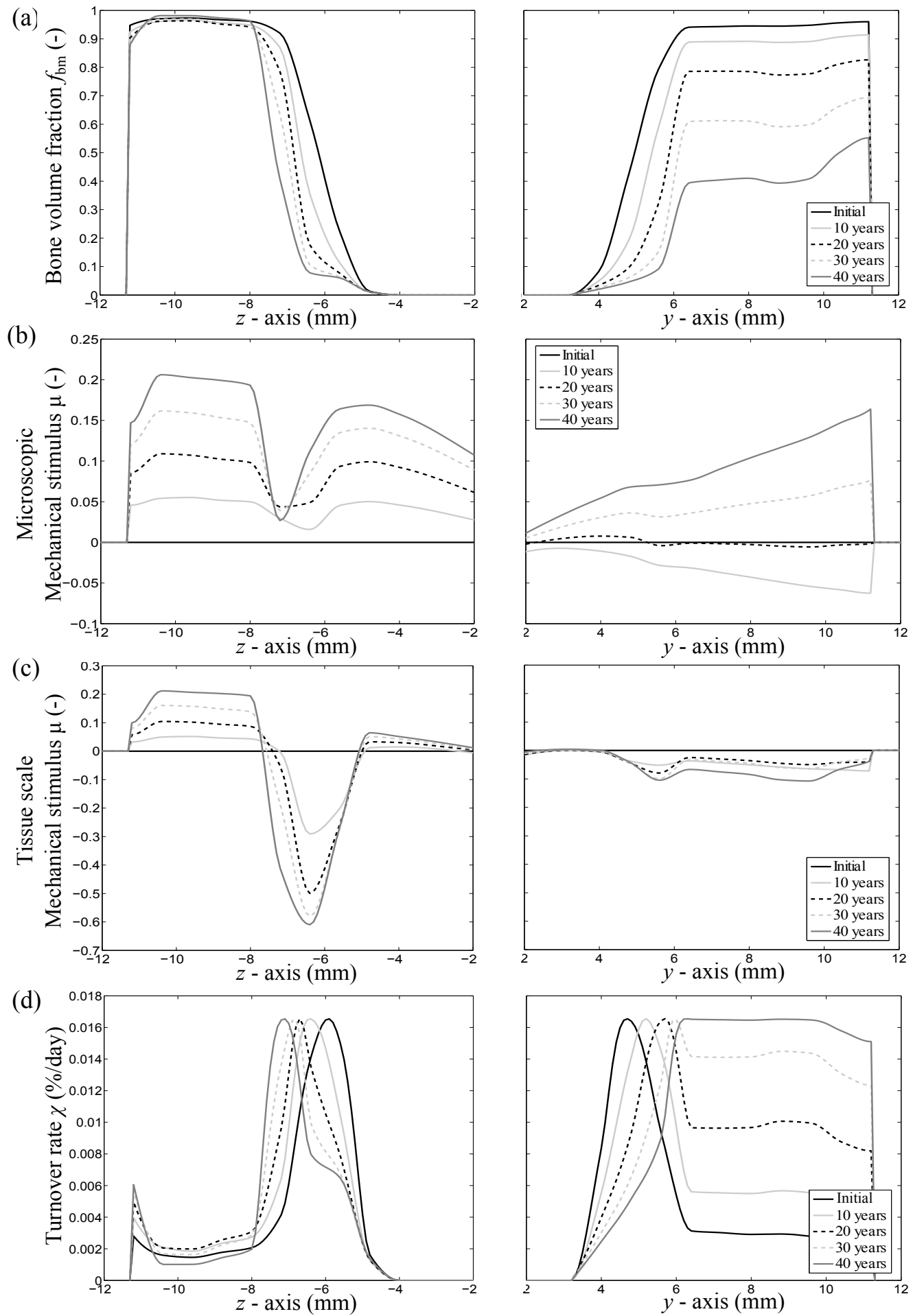

Fig. 8 Evolution of (a) Bone volume fraction; (b) Mechanical stimulus, $\mu(\boldsymbol{r}, t)$, at the microscopic scale; (c) Mechanical stimulus, $\mu(\boldsymbol{r}, t)$, at the tissue scale; and (d) Turnover rate along the $y$ and $z$-axis during the simulation of osteoporosis.

[Feik et al (1997); Parfitt (1998); Bousson et al (2001); Thomas et al (2005); Szulc et al (2006); Zebaze et al (2010)], vitamin D deficiency [Busse et al (2013)], hyperparathyroidism [Hirano et al (2000); Burr et al (2001);
Turner et al (2002)], but also during disruptions of normal mechanical loading, such as in prolonged bed rest [Leblanc et al (2007); Rittweger et al (2009)], long term space missions [Vico et al (2000); Lang et al (2004)], 

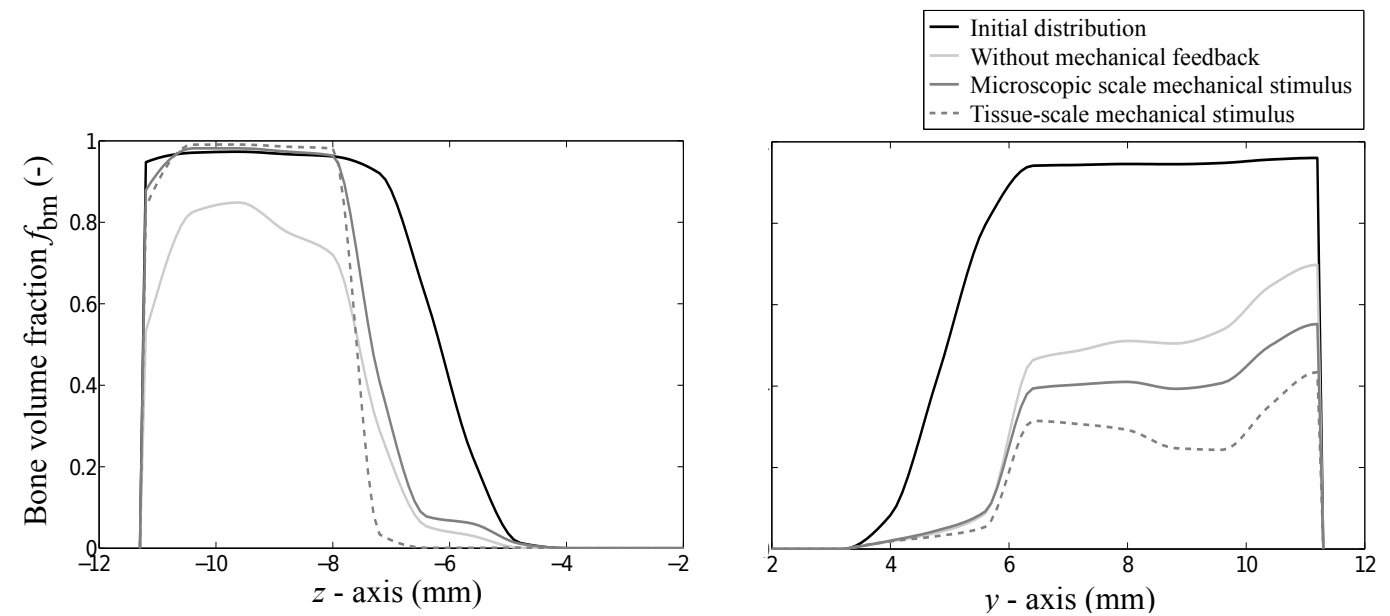

Fig. 9 Bone volume fraction along the $y$ - and $z$-axes, the initial distribution and the distributions after 40 years of simulated osteoporosis, without mechanical regulation, with mechanical regulation based on microscopic SED, and with mechanical regulation based on tissue-scale SED.

trauma-induced paralysis such as spinal cord injury [Kiratli et al (2000); Eser et al (2004)], and as well in animal studies: muscle paralysis [Warner et al (2006); Ausk et al $(2012,2013)]$ or hind-limb disuse induced by tail suspension [Bloomfield et al (2002); Judex et al (2004)].

Our numerical simulations of osteoporosis and mechanical disuse are consistent with these experimental findings. All Figures 7, 8 and 9 highlight the strong site-specificity of bone loss under deregulations of bone remodelling. The endocortical region systematically undergoes the most significant loss. This similarity arises despite the fact that in the simulation of mechanical disuse, the deregulation is non-uniform in the cross section (due to the uneven distribution of mechanical loads) whereas in the simulation of osteoporosis, the hormonal deregulation is uniform in the cross section.

The precise mechanisms that underlie the predominant loss of bone in the endocortical region are still poorly understood [Raisz and Seeman (2001); Thomas et al (2005); Squire et al (2008); Ausk et al (2012)]. Mechanical adaptation has been suggested as a potential mechanism [Frost (1997); Burr (1997); Thomas et al (2005); Jepsen and Andarawis-Puri (2012)]. Bone loss induced by mechanical disuse redistributes mechanical loads towards the periosteum, where bone volume fraction is higher. This could unload endocortical regions and thereby accelerate their resorption. Reduced physical activity and muscle strength in ageing subjects support this hypothesis [Frost (1997)]. However, the ubiquity of endocortical bone loss in situations in which mechanical loading is not significantly modified suggests that other mechanisms are at play. The morphological influence of the tissue microstructure on the rate of bone loss has been suggested to be another important factor [Martin (1972); Squire et al (2008); Zebaze et al (2010); Buenzli et al (2013)]. Cortical bone has little bone surface available to bone cells, but this surface expands during bone loss, which could increase the activation frequency of remodelling events. If remodelling is imbalanced, this may lead to an acceleration of bone loss, and to an increase of the available surface until the tissue microstructure becomes so porous that its surface area reduces with further loss [Martin (1972); Raisz and Seeman (2001)].

We have shown previously the possibility of this morphological mechanism to explain cortical bone trabecularisation in both temporal [Pivonka et al (2013)] and spatio-temporal settings [Buenzli et al (2013)]. The spatio-temporal model proposed in the present work incorporates both mechanical adaptation and a morphological feedback of the microstructure on turnover rate. In Figure 9, our simulations of osteoporosis conducted with and without mechanical feedback suggest that the rate at which the medullary cavity expands and the cortical wall thins is only marginally dependent on mechanical adaptation. This rate is primarily due to the high turnover rates present in the endocortical region (Figure 8(d)), i.e., due to the morphological influence of microstructure on the rate of loss. This proposed mechanism is consistent with the observation that distinct conditions exhibit endocortical bone loss, whether mechanical loading is disrupted or not.

\section{Model formulation of morphological feedback}

In the cell population model of Pivonka et al (2013), the morphological influence of the tissue microstructure was included through the specific surface of the tissue 
[Martin (1984); Lerebours et al (2015)] normalised by its initial value. This normalisation allowed to maintain the same cell behaviour in both cortical and trabecular bones. However, it leads to a turnover rate that is initially independent of bone volume fraction, and so the same in cortical and trabecular bone. The morphological feedback proposed in the present model differs by (i) avoiding a dependence on an initial reference state (i.e., absence of normalisation to allow microstructuredependent turnover rates), and (ii) by referring to turnover rate (a dynamic biological quantity) instead of specific surface (a morphological characterisation of the microstructure).

Whilst specific surface can be estimated directly from high-resolution scans of bone tissues [Chappard et al (2005); Squire et al (2008); Lerebours et al (2015)], quantitative links between $\mathrm{S}_{\mathrm{V}}$ and cell numbers remain unclear [Martin (1972); Parfitt (1983); Pivonka et al (2013)]. The direct reference to turnover rate, in the present model, makes the model more accurate, due to the straightforward link between turnover rate and cell populations (see Eq. (13)). Unfortunately, turnover rate is rarely measured experimentally by cell counts or volumes of bone resorbed and re-formed. It is most commonly characterised by measurements of serum concentrations of bone resorption and/or formation markers [Szulc et al (2006); Burghardt et al (2010); Malluche et al (2012)], which are difficult to relate quantitatively to cell numbers or bone volume at a particular bone site. Whilst the phenomenological relationship $\chi_{\mathrm{BV}}\left(f_{\mathrm{bm}}\right)$ that we assumed between turnover rate and microstructure remains to be studied quantitatively, such a relationship has been suggested in several studies [Felsenberg and Boonen (2005); Burghardt et al (2010); Malluche et al (2012)].

\section{Nature of the mechanical stimulus}

The nature of the mechanical stimulus sensed by bone cells and transduced into signals prompting resorption or formation has been a matter of discussion for many years. A number of computational studies simulating mechanical adaptation of bone microstructure suggested that the strain energy density could be a good candidate. Ruimerman et al (2005) tested several mechanical stimuli and concluded the SED gave best results when comparing simulations outcomes with biological parameters such as porosity, trabecular number or adaptability to external loading. However, Levenston and Carter (1998) argued that the drawback of using the SED is that it does not lead to a different response when bone is stimulated in tension or in compression. In the literature, most computational models use the SED because it is a scalar representing both microstructure and mechanical loading [Fyhrie and Carter (1986); Mullender et al (1994); Van Rietbergen et al (1999); Van Oers et al (2008); Scheiner et al (2013)]. Quantitative criteria based on experimental observations are still lacking, especially ones testing the tensorial aspects of mechanical loading conditions. For our purpose of studying tissuescale average changes in bone volume fraction, these tensorial aspects are likely to be secondary. Hence, we have based our mechanical stimulus on the strain energy density (see below for a discussion of the scale). We note here that other mechanical quantities have also been proposed and studied for their magnitude and possible influence onto osteocytes, such as fluid shear stress and fluid pressure in the lacuno-canalicular system [Knothe Tate et al (1998); Burger and Klein-Nulend (2003); Tan et al (2007); Bonewald and Johnson (2008); Adachi et al (2009b)].

Mechanical adaptation also relies on the comparison of the current mechanical state with a reference state. The definition of this reference state remains unclear [Frost (1987); Carter and Beaupré (2001)]. Our choice is to take as mechanical reference state the initial distribution of the strain energy density in the midshaft femur. This choice introduces a memory of the stimulus "normally" experienced in a certain region of the tissue. This memory effect leads to a position-dependent reference state which can be interpreted as taking into account different sensitivities of the mechano-sensing cells depending on where they are located [Skerry et al (1988); Turner et al (2002); Robling et al (2006)].

\section{Neutral axis and site-specific bone adaptation}

A common issue in models of mechanical adaptation is the risk to resorb too much bone in regions that are naturally unloaded. Such regions may exist when bending moment is large enough with respect to compressive or tensile forces. In the human midshaft femur, a neutral axis runs approximately along the antero-posterior axis [Lanyon and Rubin (1984); Cordey and Gautier (1999); Thomas et al (2005); Martelli et al (2014)]. To prevent excessive resorption in such regions, some models have considered torsional loads [Van der Meulen et al (1993); Carpenter and Carter (2008)], average values of periodic dynamic loads under which the neutral axis moves [Van der Meulen et al (1993); Carter and Beaupré (2001)], or a residual background of mechanical stimulus modelling muscle twitching and other background mechanical forces [Mittlmeier et al (1994); Carpenter and Carter (2008)].

Such additional features were not introduced explicitly in our model. The strength of the mechanical stim- 
ulus around the neutral axis remained weak in our simulation of mechanical disuse (Figure 7(a)). This is due to the fact that stimulus sensitivity is prescribed according to the initial state. The neutral axis did not move substantially during the simulation, and so the difference in strain energy density remained small. Resorption around the neutral axis was pronounced in our simulation of osteoporosis (Figures 7(b), (c) and 8) due to hormone-induced remodelling imbalance. Resorption was limited by the duration of the simulated osteoporosis (40 years) and the calibration of the overall bone loss according to experimental data.

The bending moment exerted onto the femur at the midshaft creates a strong asymmetry in the local mechanical state. Over time, this asymmetry leads to a cortical wall thickness which differs between the $y$-axis (antero-posterior axis) and the $z$-axis (lateral-medial axis), as seen in Figure 8(a). Asymmetries in cortical wall thickness and bone volume fraction, in osteoporotic patients, are commonly observed (Figure 7(d)) [Feik et al (2000); Thomas et al (2005); Zebaze et al (2010)].

\section{Microscopic vs tissue-scale mechanical regulation}

Mechanical deformations of bone matrix can be sensed by osteocytes at the microscopic, cellular scale by deformation of the cell body, transmitted either through direct contact with the matrix, or through changes in fluid flow or hydrostatic pressure [Weinbaum et al (1994); Knothe Tate (2003); Adachi et al (2009b,a); Bonewald (2011)]. However, osteocytes are highly connected to one another and to other cells in the vascular phase by an extensive network [Marotti (2000); Kerschnitzki et al (2013); Buenzli and Sims (2015)]. Whilst signal transmission mechanisms in this network remain to be determined, it is possible that the network integrates deformations of both the matrix and vascular phases before transducing them into a biochemical response, enabling a mechanical sensitivity of the network to tissue-average stresses and strains.

The uncertainty of the scale at which mechanical stimulus is sensed in bone has motivated many computational studies to estimate stress concentration effects in bone microstructures [Hipp et al (1990); Kasiri and Taylor (2008); Gitman et al (2010)]. However, few studies have explored the changes that occur during simulated bone loss when using microscopic or tissue-scale mechanical stimulus.

Our simulations of osteoporosis show that most of the difference between the mechanical stimulus at the microscopic and tissue scales occurs near the endosteum and neutral axis (Figure 8(b,c)). Changes in bone volume fraction were similar in both simulations. Stress concentration effects captured in the microscopic mechanical stimulus (but not in the tissue-scale mechanical stimulus) resulted in maintaining a region of low porosity $\left(f_{\mathrm{bm}} \simeq 0.1\right)$ near the medullary cavity and in widening the transition between endocortical and intracortical bone volume fractions (Figure 9).

Osteoporotic human femur midshafts exhibit a wide range of variability, reflecting the multiple factors influencing bone loss [Feik et al (1997, 2000); Thomas et al (2005); Zebaze et al (2010)]. The expansion of the medullary cavity and thinning of the cortical wall are commonly reported, but other changes in midshaft tissue microstructures have been studied less systematically. Depending on the subject and their specific condition, the transition between porous endocortical bone and dense intracortical bone may be sharp or wide, and highly porous microstructures near the endosteum may be found or not [Feik et al (1997), Figure 6].

Our model possesses several limitations which prevent at this stage to draw definite conclusions about the mechanical regulation of the tissue. The mechanical state is calculated only based on bone volume fraction. Other microstructural parameters such as the connectivity of the microstructure are not accounted for. Loss of connectivity is observed in osteoporotic trabecular bone [Parfitt et al (1987); Mosekilde (1990); Raisz and Seeman (2001)], which could lead to mechanical disuse and so increase in resorption. Periosteal apposition is often reported and believed to result from a compensation of endocortical bone loss in osteoporotic patients [Szulc et al (2006); Russo et al (2006); Jepsen and AndarawisPuri (2012)]. Our simulations assumed the periosteal surface to be fixed, which could limit the expansion rate of the medullary cavity. Finally, our simulation of osteoporosis assumed a constant level of physical activity. A reduction in physical activity with age could further limit the preservation of bone matrix by mechanical feedback.

\section{Summary and conclusions}

In this paper a novel spatio-temporal multiscale model of bone remodelling is proposed. This model bridges organ, tissue and cellular scales. It takes into account biochemical, geometrical, and biomechanical feedbacks. The model is applied to simulate the evolution of a human femur midshaft scan under mechanical disuse and osteoporosis. It enables us to investigate how these scales and feedbacks interact during bone loss. Our numerical simulations revealed the following findings: 
- Endocortical bone loss during both osteoporosis and mechanical disuse is driven to a large extent by sitespecific turnover rates.

- Mechanical regulation does not influence significantly the expansion rate of the medullary cavity.

- Mechanical regulation helps preserve cortical bone near the periosteum. It explains site-specific differences in the bone volume fraction distribution in the midshaft cross section during osteoporosis such as increased porosity near the neutral axis, and thicker cortical wall along the medial-lateral axis of the femur midshaft, due to the anisotropy of the mechanical stimulus in the presence of bending moments.

- The inclusion of stress concentration effects in the mechanical stimulus sensed by the bone cells has a pronounced effect on porosity in the endocortical region.

Our methodology provides a framework for the future development of patient-specific models to predict loss of bone with age or deregulating circumstances.

\section{A Complements on the model description}

A.1 Differentiation rates and signalling molecules in the cell populations model

In Section 2.3, we presented the simplified equations of the bone cells population model. Here are the developments of these equations.

$$
\begin{aligned}
& \mathcal{D}_{\mathrm{OC}_{\mathrm{u}}}(\mathrm{MCSF}, \operatorname{RANKL}(\Psi, \mathrm{PTH}))= \\
& D_{\mathrm{OC}_{\mathrm{u}}} \pi^{\mathrm{act}}\left(\frac{\mathrm{MCSF}}{k_{\mathrm{OCu}}^{\mathrm{MCSF}}}\right) \pi^{\mathrm{act}}\left(\frac{\mathrm{RANKL}}{k_{\mathrm{OC} \mathrm{u}}^{\mathrm{RANL}}}\right), \\
& \mathcal{D}_{\mathrm{OC}_{\mathrm{p}}}(\operatorname{RANKL}(\Psi, \mathrm{PTH}))=D_{\mathrm{OC}_{\mathrm{p}}} \pi^{\mathrm{act}}\left(\frac{\mathrm{RANKL}}{k_{\mathrm{OC}}^{\mathrm{RANKL}}}\right), \\
& \mathcal{A}_{\mathrm{OC}_{\mathrm{a}}}(\mathrm{TGF} \beta)=A_{\mathrm{OC}_{\mathrm{a}}} \pi^{\mathrm{act}}\left(\frac{\mathrm{TGF} \beta}{k_{\mathrm{OC}}^{\mathrm{TGF}} \beta}\right), \\
& \mathcal{D}_{\mathrm{OB}_{\mathrm{u}}}(\mathrm{TGF} \beta)=D_{\mathrm{OB}_{\mathrm{u}}} \pi^{\mathrm{act}}\left(\frac{\mathrm{TGF} \beta}{k_{\mathrm{OB}}^{\mathrm{TGF}} \beta}\right), \\
& \mathcal{D}_{\mathrm{OB}_{\mathrm{p}}}(\mathrm{TGF} \beta)=D_{\mathrm{OB}_{\mathrm{p}}} \pi^{\mathrm{rep}}\left(\frac{\mathrm{TGF} \beta}{k_{\mathrm{OB}_{\mathrm{p}}}^{\mathrm{TGF} \beta}}\right) .
\end{aligned}
$$

In those equations, several signalling molecules play a role: TGF $\beta$, RANK, RANKL, OPG, MCSF and PTH. The concentrations of these molecules follow the principles of mass action kinetics of receptor-ligand reactions. Due to the separation of scale between the cells differentiation and apoptosis rates and the receptor-ligand binding reactions, we solve them in a quasi-steady-state hypothesis:

$$
\begin{aligned}
& \operatorname{PTH}(\boldsymbol{r}, t)=\left\{\begin{array}{ll}
\mathrm{P}_{\mathrm{PTH}}, & \text { without deregulation } \\
\mathrm{P}_{\mathrm{PTH}}^{\mathrm{OP}}, & \text { whith simulated OP }
\end{array},\right. \\
& \operatorname{TGF} \beta(\boldsymbol{r}, t)=\frac{P_{\mathrm{TGF} \beta}^{\text {ext }}+n_{\mathrm{TGF} \beta}^{\mathrm{bone}} k_{\mathrm{res}} \mathrm{OC}_{\mathrm{a}}}{D_{\mathrm{TGF} \beta}} \\
& \operatorname{RANK}(\boldsymbol{r}, t)=N_{\mathrm{OC}_{\mathrm{p}}}^{\mathrm{RANK}} \mathrm{OC}_{\mathrm{p}}, \\
& \mathrm{OPG}(\boldsymbol{r}, t)=\frac{P_{\mathrm{OPG}}+\beta_{\mathrm{OB}_{\mathrm{a}}}^{\mathrm{OPG}_{\mathrm{OB}}} \pi^{\mathrm{rep}}\left(\frac{\mathrm{PTH}}{k_{\mathrm{OB}}^{\mathrm{PTH}}}\right)}{\beta_{\mathrm{OB}_{\mathrm{a}}}^{\mathrm{OPG}_{\mathrm{OB}}} \pi_{\mathrm{a}}^{\mathrm{reP}}\left(\frac{\mathrm{PTH}}{k_{\mathrm{OB}}^{\mathrm{PTH}}}\right) / \mathrm{OPG}_{\mathrm{sat}}+D_{\mathrm{OPG}}} \\
& \operatorname{RANKL}(\boldsymbol{r}, t)=\frac{\beta_{\mathrm{OB}_{\mathrm{p}}}^{\mathrm{RANL}} \mathrm{OB}_{\mathrm{p}}+\beta_{\mathrm{RANKL}}^{\text {mech }}(\Psi)}{1+k_{\mathrm{RANK}}^{\text {RANKL }} \operatorname{RANK}+k_{\mathrm{OPG}}^{\mathrm{RANL}} \mathrm{OPG}} \\
& \times\left\{D_{\mathrm{RANKL}}+\frac{\beta_{\mathrm{OB}_{\mathrm{p}}}^{\mathrm{RANL}} \mathrm{OB}_{\mathrm{p}}}{N_{\mathrm{OB}_{\mathrm{p}}}^{\mathrm{RANL}} \mathrm{OB}_{\mathrm{p}} \pi^{\text {act }}\left(\frac{\mathrm{PTH}}{k_{\mathrm{OB}}^{\mathrm{PTH}}}\right)}\right\}^{-1} .
\end{aligned}
$$

\section{A.2 Parameter values}

See Table 1.

\section{A.3 Recalibration of the model}

Since $\mathrm{OC}_{\mathrm{u}}$ and $\mathrm{OB}_{\mathrm{u}}$ vary with $f_{\mathrm{bm}}$ so as to retrieve experimentally valid turnover rates, some other parameters required modification compared with previous versions of the cell population model in which $\mathrm{OC}_{\mathrm{u}}$ and $\mathrm{OB}_{\mathrm{u}}$ were constant and uncalibrated [Buenzli et al (2012); Pivonka et al (2013)].

By comparing the cell densities between this model and the previously published one [Buenzli et al (2012)], we can determine scaling coefficients which allows a systematic calibration of $\pi^{\text {act }}\left(\frac{\mathrm{TGF} \beta}{k_{\mathrm{OC}}^{\mathrm{TGF}}}\right)$ and $\pi^{\text {act }}\left(\frac{\mathrm{RANKL}}{k_{\mathrm{OC}}^{\mathrm{R} A K L}}\right)$. Indeed, these functions depend on the active and precursor cell densities. In the original models, the constants in these functions were calibrated such as to obtain a strong biochemical feedback response. Maintaining this strong biochemical response is the aim of this re-calibration.

The calibration is realised at $f_{\mathrm{bm}}=0.90$. Both the turnover rate value and the values of $k_{\text {res }}$ and $k_{\text {form }}$, have been changed according to the literature. Hence, by isolating $\mathrm{OB}_{\mathrm{a}}$ and $\mathrm{OC}_{\mathrm{a}}$ in the two new constraints of the steady state, the active osteoblast and active osteoclast read:

$\mathrm{OC}_{\mathrm{a}}^{\text {new }}=\frac{\chi_{\mathrm{BV}}^{\text {new }}}{k_{\mathrm{res}}^{\text {new }}}=\beta \cdot \mathrm{OC}_{\mathrm{a}}$
$\mathrm{OB}_{\mathrm{a}}^{\text {new }}=\frac{k_{\mathrm{res}}^{\text {new }} \cdot \mathrm{OC}_{\mathrm{a}}^{\text {new }}}{k_{\text {form }}^{\text {new }}}=\gamma \cdot \mathrm{OB}_{\mathrm{a}}$

if $\delta$ is the coefficient of proportionality between the new bone turnover rate and the previous one; $\beta=\delta \cdot k_{\text {res }} / k_{\text {res }}^{\text {new }}$ and $\gamma=\delta \cdot k_{\text {form }} / k_{\text {form }}^{\text {new }}$. These coefficients are introduced in the determination of TGF $\beta$ and OPG. Previously, TGF $\beta$ was [Buenzli et al (2012)]:

$\mathrm{TGF} \beta=\frac{P_{\mathrm{TGF} \beta}^{\mathrm{ext}}+n_{\mathrm{TGF} \beta}^{\mathrm{bone}} k_{\mathrm{res}} \mathrm{OC}_{\mathrm{a}}}{D_{\mathrm{TGF} \beta}}$

The new one becomes:

$\mathrm{TGF} \beta^{\text {new }}=\frac{P_{\mathrm{TGF} \beta}^{\text {ext }}+n_{\mathrm{TGF} \beta}^{\text {bone }} k_{\mathrm{res}}^{\text {new }} \mathrm{OC}_{\mathrm{a}}^{\text {new }} \cdot \delta^{-1}}{D_{\mathrm{TGF} \beta}}$ 
Table 1 Nomenclature

\begin{tabular}{|c|c|c|}
\hline Symbol & Description & Value \\
\hline$\chi_{\mathrm{BV}}$ & Turnover rate & Extrapolated function of $f_{b m}$ from [Parfitt (1983)] \\
\hline $\mathrm{OB}_{\mathrm{u}}$ & Uncommitted osteoblasts & Given function of $f_{b m}$, determined to fulfil the steady state \\
\hline $\mathrm{OC}_{\mathrm{u}}$ & Uncommitted osteoclasts & Given function of $f_{b m}$, determined to fulfil the steady state \\
\hline$k_{\text {form }}$ & Daily volume of bone matrix formed per osteoblast & $150 \mu m^{3} /$ day [Buenzli et al (2014)] \\
\hline$k_{\text {res }}$ & Daily volume of bone matrix resorbed per osteoclast & $9.43 \cdot 10^{3} \mu m^{3} /$ day $[$ Buenzli et al (2014)] \\
\hline$\lambda$ & Strength of the mechanical transduction in formation & 0.5 (Parametric study) \\
\hline$\kappa$ & Strength of the mechanical transduction in resorption & $18 \mathrm{pM} /$ day (with $\left.\mu_{\mathrm{bm}}^{\mathrm{micro}}\right), 19 \mathrm{pM} /$ day (with $\left.\mu^{\mathrm{tissue}}\right)$ (Parametric study) \\
\hline $\mathbb{C}_{\mathrm{bm}}^{\mathrm{micro}}$ & Stiffness tensor of the bone matrix phase & $\left(\begin{array}{cccccc}28.4 & 11.0 & 10.4 & 0 & 0 & 0 \\
11.0 & 20.8 & 10.3 & 0 & 0 & 0 \\
10.4 & 10.3 & 18.5 & 0 & 0 & 0 \\
0 & 0 & 0 & 12.9 & 0 & 0 \\
0 & 0 & 0 & 0 & 11.5 & 0 \\
0 & 0 & 0 & 0 & 0 & 9.3\end{array}\right)$ GPa [Ashman et al (1984); Fritsch and Hellmich $\left.(2007)\right]^{4}$ \\
\hline $\mathbb{C}_{\text {vas }}^{\text {micro }}$ & Stiffness tensor of the vascular phase & $2.3 \cdot\left(\begin{array}{cccccc}1 & 1 & 1 & 0 & 0 & 0 \\
1 & 1 & 1 & 0 & 0 & 0 \\
1 & 1 & 1 & 0 & 0 & 0 \\
0 & 0 & 0 & 0 & 0 & 0 \\
0 & 0 & 0 & 0 & 0 & 0 \\
0 & 0 & 0 & 0 & 0 & 0\end{array}\right)$ GPa [Murdock (1996)] \\
\hline$N_{x}$ & Normal force & -700 N (see Section 2.1) \\
\hline$M$ & Bending moment & $50 \mathrm{Nm}$ (see Section 2.1) \\
\hline$D_{\mathrm{OC}_{\mathrm{u}}}$ & Differentiation rate of $\mathrm{OC}_{\mathrm{u}}$ into $\mathrm{OC}_{\mathrm{p}}$ & 0.42/day [Pivonka et al (2013)] \\
\hline$D_{\mathrm{OB}_{\mathrm{u}}}$ & Differentiation rate of $\mathrm{OB}_{\mathrm{u}}$ into $\mathrm{OB}_{\mathrm{p}}$ & $0.7 /$ day $^{5}$ \\
\hline$D_{\mathrm{OC}_{\mathrm{p}}}$ & Differentiation rate of $\mathrm{OC}_{\mathrm{p}}$ into $\mathrm{OC}_{\mathrm{a}}$ & $2.1 /$ day \\
\hline$D_{\mathrm{OB}_{\mathrm{p}}}$ & Differentiation rate of $\mathrm{OB}_{\mathrm{p}}$ into $\mathrm{OB}_{\mathrm{a}}$ & $0.166 /$ day \\
\hline$P_{\mathrm{OB}_{\mathrm{p}}}$ & Proliferation term of $\mathrm{OB}_{\mathrm{p}}$ & $3.5 \cdot 10^{-3} /$ day \\
\hline$A_{\mathrm{OC}_{\mathrm{a}}}$ & Apoptosis rate of $\mathrm{OC}_{\mathrm{a}}$ & $5.65 /$ day \\
\hline$A_{\mathrm{OB}_{\mathrm{a}}}$ & Apoptosis rate of $\mathrm{OB}_{\mathrm{a}}$ & $0.211 /$ day \\
\hline$k_{\mathrm{OC}_{\mathrm{a}}}^{\mathrm{TGF} \beta}$ & Parameter for $\mathrm{TGF} \beta$ binding on $\mathrm{OB}_{\mathrm{u}}$ and $\mathrm{OC}_{\mathrm{a}}$ & $5.63 \cdot 10^{-4} \mathrm{pM}$ \\
\hline$k_{\mathrm{OB}_{\mathrm{p}}}^{\mathrm{TGF} \beta}$ & Parameter for $\mathrm{TGF} \beta$ binding on $\mathrm{OB}_{\mathrm{p}}$ & $1.89 \cdot 10^{-3} \mathrm{pM}$ \\
\hline$k_{\mathrm{OB}}^{\mathrm{PTH}}$ & Parameter for PTH binding on OB (activator) & $150 \mathrm{pM}$ \\
\hline$k_{\mathrm{OB}}^{\mathrm{PTH}}$ & Parameter for PTH binding on OB (repressor) & $0.222 \mathrm{pM}$ \\
\hline$k_{\mathrm{OC}}^{\mathrm{RANKL}}$ & Parameter for RANKL binding on $\mathrm{OC}_{\mathrm{p}}$ & $16.65 \mathrm{pM}$ \\
\hline$N_{\mathrm{OC}_{\mathrm{p}}}^{\mathrm{RANK}}$ & Number of RANK receptors per $\mathrm{OC}_{p}$ & $1 \cdot 10^{4}$ \\
\hline$k_{\mathrm{OC}_{\mathrm{u}}}^{\mathrm{MCSF}}$ & Parameter for MCSF binding on $\mathrm{OC}_{\mathrm{u}}$ & $1 \cdot 10^{-3} \mathrm{pM}[$ Pivonka et al (2013)] \\
\hline $\mathrm{P}_{\mathrm{PTH}}$ & Systemic concentration of PTH & $2.907 \mathrm{pM}$ \\
\hline $\mathrm{P}_{\mathrm{PTH}}^{\mathrm{OP}}$ & $\mathrm{P}_{\mathrm{PTH}}$ when simulated osteoporosis & $2.954 \mathrm{pM}$ \\
\hline$D_{\mathrm{OPG}}$ & Degradation rate of OPG & $0.35 /$ day \\
\hline$\beta_{\mathrm{OB}_{\mathrm{a}}}^{\mathrm{OPG}}$ & Production rate of $\mathrm{OPG}$ per $\mathrm{OB}_{\mathrm{a}}$ & $1.63 \cdot 10^{8} /$ day \\
\hline $\mathrm{OPG}_{\text {sat }}$ & Saturation of OPG & $2 \cdot 10^{8} \mathrm{pM}$ \\
\hline$D_{\text {RANKL }}$ & Degradation rate of RANKL & 10/day \\
\hline$\beta_{\mathrm{OB}_{\mathrm{p}}}^{\mathrm{RANL}}$ & Production rate of RANKL per $\mathrm{OB}_{\mathrm{p}}$ & $1.68 \cdot 10^{5} /$ day \\
\hline$k_{\mathrm{OPG}}^{\mathrm{RANKL}}$ & Parameter for RANKL binding on OPG & $1 \cdot 10^{-3} / \mathrm{pM}$ \\
\hline$k_{\mathrm{RANK}}^{\mathrm{RANKL}}$ & Parameter for RANKL binding on RANK & $0.034 / \mathrm{pM}$ \\
\hline$D_{\mathrm{TGF} \beta}$ & Degradation rate of TGF $\beta$ & $2 /$ day \\
\hline$n_{\mathrm{TGF} \beta}^{\text {bone }}$ & Density of TGF $\beta$ stored in the bone matrix & $1 \cdot 10^{-2} \mathrm{pM}$ \\
\hline
\end{tabular}


The same manipulation is realised on the determination of OPG. The factor $\beta_{\mathrm{OPG}}^{\mathrm{OPG}} \mathrm{OB}_{\mathrm{a}}$ in Eq. (27), becomes $\beta_{\mathrm{OPG}}^{\mathrm{OPG}} \mathrm{OB}_{\mathrm{a}}^{\text {new }} \gamma^{-1}$
C Generalised Beam theory for inhomogeneous materials

\section{B Update frequency of mechanical state in the numerical algorithm}

In our model, to simulate osteoporosis and the change of porosity with time, we need to solve the temporal equations of the bone cell populations model, Eqs (14)-(17) and Eq. (12). Those equations via the mechanical feedback are correlated to the spatial Equations (2) and (42). Knowing the porosity distribution is required to determine the stress and strain distributions. Hence we have a semi-coupled algorithm (Figure 2).

However, due to the separation of time scale we can decompose the problem into two parts. Indeed, it takes more time for the microstructure to change significantly enough to influence the bone cell populations model. Therefore, we solve the bone cell populations model for a duration $\Delta \mathrm{t}$, assuming the mechanical feedback to be constant in this time interval. Then, we recalculate the stress and strain distributions based on the new porosity distribution, and this becomes the new mechanical feedback.

A sensitivity analysis of the solution in the time step $\Delta \mathrm{t}$ of evolution of cell densities and bone matrix volume fraction is required. For very small time steps ( $\Delta \mathrm{t} \leq 1$ day) one would expect the algorithm to converge to the exact solution. On the other hand for very large time steps ( $\Delta \mathrm{t} \geq 5$ years) a large deviation from the exact solution is expected. Figure 10 shows the evolution of the bone matrix volume fraction for one selected RVE $(y=0, z=-10 \mathrm{~mm})$ in the cross section. These simulations show that time steps of $\Delta \mathrm{t}=250$ days, 1 year and 2 years lead to very similar evolution of the bone matrix volume fraction. On the other hand, $\Delta \mathrm{t}=5$ years and 10 years lead to strong deviations from the smaller time increments. For all the simulations of 40 years of osteoporosis, we used a time step of 2 years.

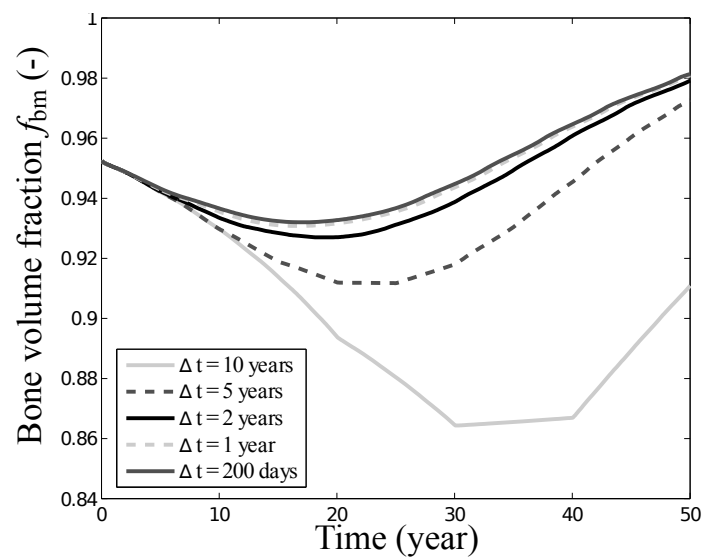

Fig. 10 The evolution of the bone matrix volume fraction for different time steps. Note that this RVE is in the intracortical region which undergoes first resorption then formation due to the redistribution of the mechanical loads.
In the following, we represent the governing equations using a Cartesian $(x, y, z)$ coordinate system. The $x$-axis represents the beam axis and coincides with the direction of the vascular pores (i.e., Haversian systems). The $y$ and $z$ coordinates describe a material point in the cross section (Figure 1(c)). The origin of the system is known as the Normal force Center: NC. Since our cross sections are inhomogeneous all the quantities, including the stiffness, are functions of $y$ and $z$.

First, based on the constitutive relation: Hooke's law, we determine the strain and stress relation:

$\boldsymbol{\sigma}^{\text {tissue }}(y, z, t)=\mathbb{C}^{\text {tissue }}(y, z, t): \varepsilon^{\text {tissue }}(y, z, t)$

where $\boldsymbol{\sigma}^{\text {tissue }}(y, z, t)$ and $\varepsilon^{\text {tissue }}(y, z, t)$ are the "tissue" stress and strain and $\mathbb{C}^{\text {tissue }}(y, z, t)$ the tissue stiffness matrix. The stiffness matrix is determined at the tissue scale, the explanation is presented in Section 2.1.

Based on the Bernoulli hypothesis, the strain distribution appears to be a plane and remains plane even after deformation. This is why we can decompose the strain by introducing three constants: $\varepsilon_{1}, \kappa_{3}$ and $\kappa_{2}$.

$\varepsilon_{x x}^{\text {tissue }}(y, z, t)=\varepsilon_{1}(t)-\kappa_{3}(t) y+\kappa_{2}(t) z$.

By introducing this relation into Hooke's law, we obtain:

$\sigma_{x x}^{\text {tissue }}(y, z, t)=\mathbb{C}_{x x}^{\text {tissue }}(y, z, t)\left(\varepsilon_{1}(t)-\kappa_{3}(t) y+\kappa_{2}(t) z\right)$

Because we assume the shear force to be null, the stress tensor is reduced to one component: $\sigma_{x x}^{\text {tissue }}(y, z, t)$. And with Bernoulli hypothesis the strain tensor contains only one component. Hence, the stiffness matrix can be replaced by the component $\mathbb{C}_{x x}^{\text {tissue }}(y, z, t)$.

Here we can see that if we determine the strain constants, we would know the stress distribution. The mechanical loadings, the inputs of this model, allow us to determine the strain. Indeed the cross section is supposed to be under a normal force: $\boldsymbol{N}$ and a bending moment $\boldsymbol{M}$ here divided in two bending moments: $M_{y}$ and $M_{z}$, such as $M \hat{\boldsymbol{m}}=M_{y} \hat{\boldsymbol{y}}+M_{z} \hat{\boldsymbol{z}}$. By definition of the stress we have the relations:

$$
\begin{aligned}
N & =\int \sigma_{x x}^{\mathrm{tissue}}(y, z, t) d A \\
M_{y} & =\int z \cdot \sigma_{x x}^{\mathrm{tissue}}(y, z, t) d A \\
M_{z} & =-\int y \cdot \sigma_{x x}^{\mathrm{tissue}}(y, z, t) d A
\end{aligned}
$$

By introducing the static moments of first and second order: $E A, E S_{y}, E S_{z}, E I_{y y}, E I_{z z}, E I_{y z}$, the equations become the following constitutive relation:

$$
\left[\begin{array}{c}
N \\
M_{y} \\
M_{z}
\end{array}\right]=\left[\begin{array}{ccc}
E A & E S_{y} & E S_{z} \\
E S_{y} & E I_{y y} & E I_{y z} \\
E S_{z} & E I_{y z} & E I_{z z}
\end{array}\right]\left[\begin{array}{c}
\varepsilon_{1} \\
\kappa_{2} \\
\kappa_{3}
\end{array}\right]
$$


where:

$$
\begin{aligned}
& E A=\int \mathbb{C}_{x x}^{\text {tissue }}(y, z, t) d A \\
& E S_{y}=\int \mathbb{C}_{x x}^{\text {tissue }}(y, z, t) \cdot y d A \\
& E I_{y y}=\int \mathbb{C}_{x x}^{\text {tissue }}(y, z, t) \cdot y^{2} d A \\
& E S_{z}=\int \mathbb{C}_{x x}^{\text {tissue }}(y, z, t) \cdot z d A \\
& E I_{z y}=\int \mathbb{C}_{x x}^{\text {tissue }}(y, z, t) \cdot y z d A=E I_{y z} \\
& E I_{z z}=\int \mathbb{C}_{x x}^{\text {tissue }}(y, z, t) \cdot z^{2} d A
\end{aligned}
$$

If we chose the origin of the coordinate system at the normal center (NC) of the cross section, the coupling terms between extension and bending vanish since they become null by definition of the NC:

$E S_{y}=\int \mathbb{C}_{x x}^{\mathrm{tissue}}(y, z, t) \cdot y d A=0$

$E S_{z}=\int \mathbb{C}_{x x}^{\text {tissue }}(y, z, t) \cdot z d A=0$

The constitutive relation can be simplified as:

$$
\left[\begin{array}{c}
N \\
M_{y} \\
M_{z}
\end{array}\right]=\left[\begin{array}{ccc}
E A & 0 & 0 \\
0 & E I_{y y} & E I_{y z} \\
0 & E I_{y z} & E I_{z z}
\end{array}\right]\left[\begin{array}{c}
\varepsilon_{1} \\
\kappa_{2} \\
\kappa_{3}
\end{array}\right]
$$

\section{Determination of the Normal Force Center NC}

The special location of the origin of the coordinate system for which the coupling terms ( $E S_{y}$ and $E S_{z}$ ) between extension and bending become zero is by definition called the normal force center NC. The result of this definition is that an axial force $\boldsymbol{N}$ which acts at the $\mathrm{NC}$ only causes straining and no bending. The coupling terms are also referred to as weighted static moments or weighted first order moments. To find the position of the coordinate system for which the coupling terms become zero requires a tool.

Assume a temporary coordinate system: $\bar{y}-\bar{z}$ from which the porosity distribution is known. The shift in origin of this coordinate system with respect to the $y-z$ coordinate system through the unknown NC is denoted with $\bar{y}_{N C}$ and $\bar{z}_{N C}$. The temporary coordinate system can be expressed in terms of the $y-z$ coordinate system as:

$$
\bar{y}=y+\bar{y}_{N C} \quad \bar{z}=z+\bar{z}_{N C}
$$

Hence:

$$
\begin{aligned}
E S_{\bar{y}} & =\int \mathbb{C}_{x x}^{\mathrm{tissue}}(y, z, t) \cdot \bar{y} d A \\
& =\int \mathbb{C}_{x x}^{\mathrm{tissue}}(y, z, t) \cdot y d A+\bar{y}_{N C} \int \mathbb{C}_{x x}^{\mathrm{tissue}}(y, z, t) d A \\
& =E S_{y}+E A \cdot \bar{y}_{N C} \\
E S_{\bar{z}} & =\int \mathbb{C}_{x x}^{\mathrm{tissue}}(y, z, t) \cdot \bar{z} d A \\
& =\int \mathbb{C}_{x x}^{\mathrm{tissue}}(y, z, t) \cdot z d A+\bar{z}_{N C} \int \mathbb{C}_{x x}^{\mathrm{tissue}}(y, z, t) d A \\
& =E S_{z}+E A \cdot \bar{z}_{N C}
\end{aligned}
$$

By definition $E S_{y}$ and $E S_{z}$ with respect to the $y-z$ coordinate system are zero. From which the unknown position of the NC with respect to the known position of the $\bar{y}-\bar{z}$ coordinate system can be found:

$\bar{y}_{N C}=\frac{E S_{\bar{y}}}{E A}$

$\bar{z}_{N C}=\frac{E S_{\bar{z}}}{E A}$

To conclude, here is the step-by-step methodology we are using to find the stress and strain distribution in the cross section:

1. Localise the normal center (NC) by computing the integrations: $E A, E S_{y}, E S_{z}$.

2. Compute the integrations: $E I_{y y}, E I_{z z}$ and $E I_{y z}$.

3. Determine the cross-sectional forces: $\boldsymbol{N}, M_{y}$ and $M_{z}$.

4. Calculate the cross-sectional deformations: $\varepsilon_{1}, \kappa_{2}$ and $\kappa_{3}$ based on Eqn. (42).

5. Find the strain distribution based on the kinematic relation, Eqn. (34). Here it is important to remember to use the coordinate centred in NC.

6. Find the stress distribution based on Hookes' law, Eqn. (33).

The initial cross section is extracted from a microradiograph, as it is explained in Section 2.4; and the mechanical loading is not symmetrical. Hence the position of the NC is changing. This is why we need to localise it after each step.

Conflict of Interest The authors declare that they have no conflict of interest.

Acknowledgements We thank C. David L. Thomas and Prof. John G. Clement for providing the microradiographs of the femur cross sections. PRB is the recipient of an Australian Research Council Discovery Early Career Research Award (DE130101191).

\section{References}

Adachi T, Aonuma Y, Ito SI, Tanaka M, Hojo M, TakanoYamamoto T, Kamioka H (2009a) Osteocyte calcium signaling response to bone matrix deformation. Journal of Biomechanics 42(15):2507-2512

Adachi T, Aonuma Y, Tanaka M, Hojo M, Takano-Yamamoto $\mathrm{T}$, Kamioka H (2009b) Calcium response in single osteocytes to locally applied mechanical stimulus: Differences in cell process and cell body. Journal of Biomechanics 42(12):1989-1995, DOI 10.1016/j.jbiomech.2009.04.034

Ashman R, Cowin S, Van Buskirk W, Rice J (1984) A continuous wave technique for the measurement of the elastic properties of cortical bone. Journal of Biomechanics 17(5):349-361, DOI 10.1016/0021-9290(84)90029-0

Ausk BJ, Huber P, Poliachik SL, Bain SD, Srinivasan S, Gross TS (2012) Cortical bone resorption following muscle paralysis is spatially heterogeneous. Bone 50(1):14-22

Ausk BJ, Huber P, Srinivasan S, Bain SD, Kwon RY, McNamara EA, Poliachik SL, Sybrowsky CL, Gross TS (2013) Metaphyseal and diaphyseal bone loss in the tibia following transient muscle paralysis are spatiotemporally distinct resorption events. Bone 57(2):413-422

Bauchau OA, Craig JI (2009) Structural Analysis. With Applications to Aerospace Structures, solid mech edn. Springer 
Bloomfield SA, Allen MR, Hogan HA, Delp MD (2002) Siteand compartment-specific changes in bone with hindlimb unloading in mature adult rats. Bone 31(1):149-157

Bonewald LF (2011) The amazing osteocyte. Journal of Bone and Mineral Research 26(2):229-38

Bonewald LF, Johnson ML (2008) Osteocytes, mechanosensing and Wnt signaling. Bone 42(4):606-15

Bousson V, Meunier A, Bergot C, Vicaut E, Rocha MA, Morais MH, Laval-Jeantet AM, Laredo JD (2001) Distribution of intracortical porosity in human midfemoral cortex by age and gender. Journal of Bone and Mineral Research 16(7):1308-17, DOI 10.1359/jbmr.2001.16.7.1308

Buenzli PR, Sims NA (2015) Quantifying the osteocyte network in the human skeleton. Bone (In Press), DOI 10.1016/j.bone.2015.02.016

Buenzli PR, Pivonka P, Gardiner BS, Smith DW (2012) Modelling the anabolic response of bone using a cell population model. Journal of Theoretical Biology 307:42-52

Buenzli PR, Thomas CDL, Clement JG, Pivonka P (2013) Endocortical bone loss in osteoporosis: the role of bone surface availability. International Journal for Numerical Methods in Biomedical Engineering 29(12):1307-22, DOI 10.1002/cnm.2567

Buenzli PR, Pivonka P, Smith DW (2014) Bone refilling in cortical basic multicellular units: insights into tetracycline double labelling from a computational model. Biomechanics and Modeling in Mechanobiology 13(1):185-203, DOI 10.1007/s10237-013-0495-y

Burger EH, Klein-Nulend TH Jand Smit (2003) Strain-derived canalicular fluid flow regulates osteoclast activity in a remodelling osteon - A proposal. Journal of Biomechanics 36:1453-1459, DOI 10.1016/S0021-9290(03)00126-X

Burghardt AJ, Kazakia GJ, Sode M, de Papp AE, Link TM, Majumdar S (2010) A longitudinal HR-pQCT study of alendronate treatment in postmenopausal women with low bone density: Relations among density, cortical and trabecular microarchitecture, biomechanics, and bone turnover. Journal of Bone and Mineral Research 25(12):2558-71

Burr D (1997) Muscle Strength, Bone Mass, and Age Related Bone Loss. Journal of Bone and Mineral Research 12(10):1547-1551, DOI 10.1359/jbmr.1997.12.10.1547

Burr DB, Hirano T, Turner CH, Hotchkiss C, Brommage R, Hock JM (2001) Intermittently administered human parathyroid hormone(1-34) treatment increases intracortical bone turnover and porosity without reducing bone strength in the humerus of ovariectomized cynomolgus monkeys. Journal of Bone and Mineral Research 16(1):157165, DOI 10.1359/jbmr.2001.16.1.157

Busse B, Bale HA, Zimmermann EA, Panganiban B, Barth HD, Carriero A, Vettorazzi E, Zustin J, Hahn M, Ager JW, Püschel K, Amling M, Ritchie RO (2013) Vitamin D deficiency induces early signs of aging in human bone, increasing the risk of fracture. Science Translational Medicine 5(193):1-11, DOI 10.1126/scitranslmed.3006286

Carpenter RD, Carter DR (2008) The mechanobiological effects of periosteal surface loads. Biomechanics and Modeling in Mechanobiology 7(3):227-42, DOI 10.1007/s10237007-0087-9

Carter DR, Beaupré GS (2001) Skeletal function and form. Cambridge University Press

Carter DR, Hayes WC (1977) The Compressive Behavior Porous of Bone Structure as a Two-Phase. The Journal of Bone and Joint Surgery 59(7):954-962

Chappard D, Retailleau-Gaborit N, Legrand E, Baslé MF, Audran M (2005) Comparison insight bone measurements by histomorphometry and microCT. Journal of Bone and
Mineral Research 20(7):1177-84

Christen P, Ito K, Müller R, Rubin MR, Dempster DW, Bilezikian JP, Van Rietbergen B (2012) Patient-specific bone modelling and remodelling simulation of hypoparathyroidism based on human iliac crest biopsies. Journal of Biomechanics 45(14):2411-6

Christen P, Ito K, Santos AAD, Müller R, B van Rietbergen (2013) Validation of a bone loading estimation algorithm for patient-specific bone remodelling simulations. Journal of Biomechanics 46(5):941-8

Collet P, Uebelhart D, Vico L, Moro L, Hartmann D, Roth M, Alexandre C (1997) Effects of 1- and 6-Month Spaceflight on Bone Mass and Biochemistry in Two Humans. Bone 20(6):547-551

Cordey J, Gautier E (1999) Strain gauges used in the mechanical testing of bones. Part III: Strain analysis, graphic determination of the neutral axis. Injury 30:S-A21-SA25

Dempster DW, Compston JE, Drezner MK, Glorieux FH, Kanis JA, Malluche H, Meunier PJ, Ott SM, Recker RR, Parfitt AM (2013) Standardized nomenclature, symbols, and units for bone histomorphometry: a 2012 update of the report of the ASBMR Histomorphometry Nomenclature Committee. Journal of Bone and Mineral Research 28(1):2-17, DOI 10.1002/jbmr.1805

Eser P, Frotzler A, Zehnder Y, Wick L, Knecht H, Denoth J, Schiessl H (2004) Relationship between the duration of paralysis and bone structure: A pQCT study of spinal cord injured individuals. Bone 34:869-880

Eshelby JD (1957) The Determination of the Elastic Field of an Ellipsoidal Inclusion, and Related Problems. Proceedings of the Royal Society A: Mathematical, Physical and Engineering Sciences 241(1226):376-396

Feik SA, Thomas CD, Clement JG (1997) Age-related changes in cortical porosity of the midshaft of the human femur. Journal of Anatomy 191:407-16

Feik SA, Thomas CD, Bruns R, Clement JG (2000) Regional variations in cortical modeling in the femoral mid-shaft: sex and age differences. American Journal of Physical Anthropology 112(2):191-205

Felsenberg D, Boonen S (2005) The bone quality framework: determinants of bone strength and their interrelationships, and implications for osteoporosis management. Clinical Therapeutics 27(1):1-11

Forner-Cordero A, Koopman HJFM, Van der Helm FCT (2006) Inverse dynamics calculations during gait with restricted ground reaction force information from pressure insoles. Gait \& Posture 23(2):189-99

Fritsch A, Hellmich C (2007) 'Universal' microstructural patterns in cortical and trabecular, extracellular and extravascular bone materials: micromechanics-based prediction of anisotropic elasticity. Journal of Theoretical Biology 244(4):597-620, DOI 10.1016/j.jtbi.2006.09.013

Fritsch A, Hellmich C, Dormieux L (2009) Ductile sliding between mineral crystals followed by rupture of collagen crosslinks: experimentally supported micromechanical explanation of bone strength. Journal of Theoretical Biology 260(2):230-52, DOI 10.1016/j.jtbi.2009.05.021

Frost HM (1987) Bone "mass" and the "mechanostat": a proposal. The Anatomical Record 219(1):1-9, DOI 10.1002/ar.1092190104

Frost HM (1997) On our age-related bone loss: insights from a new paradigm. Journal of Bone and Mineral Research 12(10):1539-1546, DOI 10.1359/jbmr.1997.12.10.1539

Frost HM (2003) Bone's mechanostat: a 2003 update. The Anatomical Record Part A, Discoveries in molecular, cel- 
lular, and evolutionary biology 275(2):1081-101, DOI 10.1002/ar.a.10119

Fyhrie DP, Carter DR (1986) A unifying principle relating stress to trabecular bone morphology. Journal of Orthopaedic Research 4(3):304-317

Fyhrie DP, Kimura JH (1999) Cancellous bone biomechanics. Journal of Biomechanics 32(11):1139-1148, DOI 10.1016/S0021-9290(99)00114-1

García-Aznar JM, Rueberg T, Doblare M (2005) A bone remodelling model coupling micro-damage growth and repair by 3D BMU-activity. Biomechanics and Modeling in Mechanobiology 4(2-3):147-67, DOI 10.1007/s10237-0050067-x

Gitman IM, Askes H, Kuhl E, Aifantis EC (2010) Stress concentrations in fractured compact bone simulated with a special class of anisotropic gradient elasticity. International Journal of Solids and Structures 47(9):1099-1107, DOI 10.1016/j.ijsolstr.2009.11.020

Hellmich C, Ulm FJ, Dormieux L (2004) Can the diverse elastic properties of trabecular and cortical bone be attributed to only a few tissue-independent phase properties and their interactions? Arguments from a multiscale approach. Biomechanics and Modeling in Mechanobiology 2(4):219-38, DOI 10.1007/s10237-004-0040-0

Hellmich C, Kober C, Erdmann B (2008) Micromechanicsbased conversion of CT data into anisotropic elasticity tensors, applied to FE simulations of a mandible. Annals of Biomedical Engineering 36(1):108-22, DOI 10.1007/s10439-007-9393-8

Hernandez CJ, Beaupré GS, Keller TS, Carter DR (2001) The influence of bone volume fraction and ash fraction on bone strength and modulus. Bone 29(1):74-8

Hill R (1963) Elastic properties of reinforced solids. Journal of the Mechanics and Physics of Solids 11(5):357-372

Hill R (1965) A self-consistent mechanics of composite materials. Journal of the Mechanics and Physics of Solids 13(4):213-222, DOI 10.1016/0022-5096(65)90010-4

Hipp JA, Edgerton BC, An KN, Hayes WC (1990) Structural consequences of transcortical holes in long bones loaded in torsion. Journal of Biomechanics 23:1261-1268

Hirano T, Burr DB, Cain RL, Hock JM (2000) Changes in geometry and cortical porosity in adult, ovary-intact rabbits after 5 months treatment with LY333334 (hPTH 1-34). Calcified Tissue International 66:456-460, DOI $10.1007 / \mathrm{s} 002230010091$

Hjelmstad KD (2005) Fundamentals of Structural Mechanics, 2nd edn. Springer

Huiskes R, Ruimerman R, Van Lenthe GH, Janssen JD (2000) Effects of mechanical forces on maintenance and adaptation of form in trabecular bone. Nature 405(6787):704-6, DOI 10.1038/35015116

Jepsen KJ, Andarawis-Puri N (2012) The amount of periosteal apposition required to maintain bone strength during aging depends on adult bone morphology and tissue-modulus degradation rate. Journal of Bone and Mineral Research 27(9):1916-26, DOI 10.1002/jbmr.1643

Judex S, Garman R, Squire M, Busa B, Donahue LR, Rubin C (2004) Genetically linked site-specificity of disuse osteoporosis. Journal of Bone and Mineral Research 19(4):607613, DOI 10.1359/JBMR.040110

Kasiri S, Taylor D (2008) A critical distance study of stress concentrations in bone. Journal of Biomechanics 41:603609, DOI 10.1016/j.jbiomech.2007.10.003

Kerschnitzki M, Kollmannsberger P, Burghammer M, Duda GN, Weinkamer R, Wagermaier W, Fratzl P (2013) Architecture of the osteocyte network correlates with bone material quality. Journal of Bone and Mineral Research 28(8):1837-1845, DOI 10.1002/jbmr.1927

Kiratli BJ, Smith AE, Nauenberg T, Kallfelz CF, Perkash I (2000) Bone mineral and geometric changes through the femur with immobilization due to spinal cord injury. Journal of Rehabilitation Research and Development 37:225-233

Knothe Tate ML (2003) Whither flows the fluid in bone? An osteocyte's perspective. Journal of Biomechanics 36(10):1409-1424, DOI 10.1016/S0021-9290(03)00123-4

Knothe Tate ML, Knothe U, Niederer P (1998) Experimental eludication of mechanical load-induced fluid flow and its potential role in bone metabolism and functional adaptation. American Journal of the Medical Sciences 316(3):189195

Lang T, LeBlanc A, Evans H, Lu Y, Genant H, Yu A (2004) Cortical and trabecular bone mineral loss from the spine and hip in long-duration spaceflight. Journal of Bone and Mineral Research 19(6):1006-1012

Lanyon LE, Rubin CT (1984) Static vs dynamic loads as an influence on bone remodelling. Journal of Biomechanics 17(12):897-905

Lanyon LE, Goodship AE, Pye CJ, MacFie JH (1982) Mechanically adaptive bone remodelling. Journal of Biomechanics 15(3):141-154

Laws N (1977) The determination of stress and strain concentrations at an ellipsoidal inclusion in an anisotropic material. Journal of Elasticity 7(1):91-97

Leblanc AD, Spector ER, Evans HJ, Sibonga JD (2007) Skeletal responses to space flight and the bed rest analog: A review. Journal of Musculoskeletal Neuronal Interactions $7(1): 33-47$

Lemaire V, Tobin FL, Greller LD, Cho CR, Suva LJ (2004) Modeling the interactions between osteoblast and osteoclast activities in bone remodeling. Journal of Theoretical Biology 229(3):293-309, DOI 10.1016/j.jtbi.2004.03.023

Lerebours C, Thomas C, Clement J, Buenzli P, Pivonka P (2015) The relationship between porosity and specific surface in human cortical bone is subject specific. Bone 72:109 - 117, DOI 10.1016/j.bone.2014.11.016

Levenston ME, Carter DR (1998) An energy dissipation-based model for damage stimulated bone adaptation. Journal of Biomechanics 31(7):579-586

Lloyd DG, Besier TF (2003) An EMG-driven musculoskeletal model to estimate muscle forces and knee joint moments in vivo. Journal of Biomechanics 36(6):765-776, DOI 10.1016/S0021-9290(03)00010-1

Malluche HH, Porter DS, Monier-Faugere M, Mawad H, Pienkowski D (2012) Differences in bone quality in low- and high-turnover renal osteodystrophy. Journal of the American Society of Nephrology 23(3):525-32, DOI 10.1681/ASN.2010121253

Marotti G (2000) The osteocyte as a wiring transmission system. Journal of Musculoskeletal \& Neuronal Interactions $1(2): 133-6$

Martelli S, Pivonka P, Ebeling PR (2014) Femoral shaft strains during daily activities: Implications for atypical femoral fractures. Clinical Biomechanics 29(8):869-876, DOI 10.1016/j.clinbiomech.2014.08.001

Martin RB (1972) Effects of geometric feedback in osteoporosis. Journal of Biomechanics 5:447-455

Martin RB (1984) Porosity and specific surface of bone. Critical Reviews in Biomedical Engineering 10(3):179-222

Martin RB, Burr DB, Sharkey NA (1998) Skeletal Tissue Mechanics. Springer

Martin TJ (2004) Paracrine regulation of osteoclast formation and activity: milestones in discovery. Journal of Muscu- 
loskeletal \& Neuronal Interactions 4(3):243-53

McNamara LM, Prendergast PJ (2007) Bone remodelling algorithms incorporating both strain and microdamage stimuli. Journal of Biomechanics 40(6):1381-91

Mittlmeier T, Mattheck C, Dietrich F (1994) Effects of mechanical loading on the profile of human femoral diaphyseal geometry. Medical Engineering \& Physics 16:75-81, DOI 10.1016/1350-4533(94)90014-0

Morin C, Hellmich C (2014) A multiscale poromicromechanical approach to wave propagation and attenuation in bone. Ultrasonics 54(5):1251-1269, DOI 10.1016/j.ultras.2013.12.005

Mosekilde L (1990) Consequences of the Remodeling Process for Vertebral Trabecular Bone-Structure - a Scanning Electron-Microscopy Study (Uncoupling of Unloaded Structures). Bone and Mineral 10:13-35

Mullender MG, Huiskes R, Weinans H (1994) A Physiological Approach to the Simulation of Bone remodeling as a Selforganizational Control Process. Journal of Biomechanics 27(11):1389-1394

Murdock J (1996) Mechanics of Fluids. In: Mark's Standard Handbook for Mechanical Engineers, 10th edn, McGrawHill, pp 3.29-3.61

Nordin BEC, Need AG, Chatterton BE, Horowitz M, Morris HA (1988) The Relative Contributions of Age and Years since Menopause to Postmenopausal Bone Loss. Journal of Clinical Endocrinology and Metabolism 70(1):83-88

Parfitt A (1983) The Physiologic and Clinical significance of Bone Histomorphometric Data. In: Recker R (ed) Bone histomorphometry: Techniques and Interpretation, CRC Press, Boca Raton, chap 9, pp 143-224

Parfitt A (1998) A structural Approach to Renal Bone Disease. Journal of Bone and Mineral Research 13(8):1213-1220

Parfitt A, Chir B (1987) Bone remodeling and bone loss: Understanding the Pathophysiology of Osteoporosis. Clinical Obstetrics and Gynecology 30(4):789-811

Parfitt AM, Drezner MK, Glorieux FH, Kanis JA, Malluche H, Meunier PJ, Ott SM, Recker RR (1987) Bone histomorphometry: standardization of nomenclature, symbols, and units. Report of the ASBMR Histomorphometry Nomenclature Committee. Journal of Bone and Mineral Research 2(6):595-610, DOI 10.1002/jbmr.5650020617

Pettermann H, Reiter T, Rammerstorfer F (1997) Computational Simulation of Internal Bone remodeling. Archives of Computational Methods of Engineering 4(4):295-323

Pivonka P, Zimak J, Smith DW, Gardiner BS, Dunstan CR, Sims NA, Martin TJ, Mundy GR (2008) Model structure and control of bone remodeling: a theoretical study. Bone 43(2):249-63, DOI 10.1016/j.bone.2008.03.025

Pivonka P, Zimak J, Smith DW, Gardiner BS, Dunstan CR, Sims Na, Martin TJ, Mundy GR (2010) Theoretical investigation of the role of the RANK-RANKL-OPG system in bone remodeling. Journal of Theoretical Biology 262(2):306-16, DOI 10.1016/j.jtbi.2009.09.021

Pivonka P, Buenzli PR, Dunstan CR (2012) A Systems Approach to Understanding Bone Cell Interactions in Health and Disease. S. Gowder

Pivonka P, Buenzli PR, Scheiner S, Hellmich C, Dunstan CR (2013) The influence of bone surface availability in bone remodelling A mathematical model including coupled geometrical and biomechanical regulations of bone cells. Engineering Structures 47:134-147

Prendergast PJ, Taylor D (1994) Prediction of bone adaptation using damage accumulation. Journal of Biomechanics 27(8):1067-76
Raisz LG, Seeman E (2001) Causes of age-related bone loss and bone fragility: an alternative view. Journal of Bone and Mineral Research 16(11):1948-1952

Rho JY, Kuhn-Spearing L, Zioupos P (1998) Mechanical properties and the hierarchical structure of bone. Medical Engineering \& Physics 20(2):92-102

Rittweger J, Simunic B, Bilancio G, Gaspare De Santo N, Cirillo M, Biolo G, Pisot R, Eiken O, Mekjavic IB, Narici M (2009) Bone loss in the lower leg during 35 days of bed rest is predominantly from the cortical compartment. Bone 44(4):612-618, DOI 10.1016/j.bone.2009.01.001

Robling AG, Castillo AB, Turner CH (2006) Biomechanical and molecular regulation of bone remodeling. Annual Review of Biomedical Engineering 8:455-98

Roodman GD (1999) Cell biology of the osteoclast. Experimental Hematology 27(8):1229-41

Ruff CB (2000) Body size, body shape, and long bone strength in modern humans. Journal of Human Evolution 38(2):269-90, DOI 10.1006/jhev.1999.0322

Ruimerman R, Van Rietbergen B, Hilbers P, Huiskes R (2005) The effects of trabecular-bone loading variables on the surface signaling potential for bone remodeling and adaptation. Annals of Biomedical Engineering 33(1):71-8

Russo CR, Lauretani F, Seeman E, Bartali B, Bandinelli S, Di Iorio A, Guralnik J, Ferrucci L (2006) Structural adaptations to bone loss in aging men and women. Bone 38:112118, DOI 10.1016/j.bone.2005.07.025

Salencon J (2001) Handbook of Continuum Mechanics (General Concepts, Thermoelasticity), 1st edn. Berlin: Springer

Scheiner S, Pivonka P, Hellmich C (2013) Coupling systems biology with multiscale mechanics, for computer simulations of bone remodeling. Computer Methods in Applied Mechanics and Engineering 254:181-196, DOI 10.1016/j.cma.2012.10.015

Skerry TM, Bitensky L, Chayen J, Lanyon LE (1988) LoadingRelated Reorientation of Bone Proteoglycan in Vivo . Strain Memory in Bone Tissue ? Journal of Orthopaedic Research 6(4):547-551

Squire M, Brazin A, Keng Y, Judex S (2008) Baseline bone morphometry and cellular activity modulate the degree of bone loss in the appendicular skeleton during disuse. Bone 42(2):341-9, DOI 10.1016/j.bone.2007.09.052

Szulc P, Seeman E, Duboeuf F, Sornay-Rendu E, Delmas PD (2006) Bone fragility: failure of periosteal apposition to compensate for increased endocortical resorption in postmenopausal women. Journal of Bone and Mineral Research 21(12):1856-63, DOI 10.1359/jbmr.060904

Tan SD, de Vries TJ, Kuijpers-Jagtman AM, Semeins CM, Everts V, Klein-Nulend J (2007) Osteocytes subjected to fluid flow inhibit osteoclast formation and bone resorption. Bone 41:745-751, DOI 10.1016/j.bone.2007.07.019

Thomas CDL, Feik SA, Clement JG (2005) Regional variation of intracortical porosity in the midshaft of the human femur: age and sex differences. Journal of Anatomy 206(2):115-25, DOI 10.1111/j.1469-7580.2005.00384.x

Timoshenko S, Goodier JN (1951) Theory of Elasticity, newyork edn. McGraw-Hill

Turner CH, Robling AG, Duncan RL, Burr DB (2002) Do bone cells behave like a neuronal network? Calcified Tissue International 70(6):435-42

Van der Meulen MCH, Beaupre GS, Carter DR (1993) Mechanobiologic influences in long bone cross-sectional growth. Bone 14(4):635-642

Van Oers RFM, Ruimerman R, Tanck E, Hilbers PAJ, Huiskes R (2008) A unified theory for osteonal and hemi-osteonal remodeling. Bone 42(2):250-9, DOI 
10.1016/j.bone.2007.10.009

Van Rietbergen B, Müller R, Ulrich D, Rüegsegger P, Huiskes $R$ (1999) Tissue stresses and strain in trabeculae of a canine proximal femur can be quantified from computer reconstructions. Journal of Biomechanics 32(4):443-51

Vaughan CL, Davis BL, O'Connor JC (1992) Dynamics of Human Gait. Kiboho Publishers

Viceconti M, Testi D, Taddei F, Martelli S, Clapworthy GJ, Jan S (2006) Biomechanics Modeling of the Musculoskeletal Apparatus : Status and Key Issues. Proceedings of the IEEE 94(4):725-739

Vico L, Collet P, Guignandon A, Lafage-Proust MH, Thomas T, Rehailia M, Alexandre C (2000) Effects of long-term microgravity exposure on cancellous and cortical weightbearing bones of cosmonauts. The Lancet 355(9215):16071611, DOI 10.1016/S0140-6736(00)02217-0

Warner SE, Sanford DA, Becker BA, Bain SD, Srinivasan S, Gross TS (2006) Botox induced muscle paralysis rapidly degrades bone. Bone 38:257-264

Weinans H, Huiskes R, Grootenboer HJ (1992) The behavior of adaptive bone-remodeling simulation models. Journal of Biomechanics 25(12):1425-1441

Weinbaum S, Cowin S, Zeng Y (1994) A model for the excitation of osteocytes by mechanical loading-induced bone fluid shear stresses. Journal of Biomechanics 27(3):339360, DOI 10.1016/0021-9290(94)90010-8

Weiner S, Wagner HD (1998) The material bone: StructureMechanical Function Relations. Annual Review of Materials Science 28(1):271-298

Zaoui A (1997) Structural morphology and constitutive behavior of microheterogeneous materials. In: Suquet P (ed) Continuum Micromechanics, Springer-Verlag, Wien, pp 291-347

Zaoui A (2002) Continuum Micromechanics: Survey. Journal of Engineering Mechanics 128(August):808-816

Zebaze RMD, Ghasem-Zadeh A, Bohte A, Iuliano-Burns S, Mirams M, Price RI, Mackie EJ, Seeman E (2010) Intracortical remodelling and porosity in the distal radius and postmortem femurs of women: a cross-sectional study. Lancet 375(9727):1729-36, DOI 10.1016/S0140-6736(10)60320-0 